\title{
Guanylation of Thiosemicarbazones: A New Synthetic Route to Polysubstituted Guanylhydrazones with Antimicrobial Activity
}

\author{
Silvio Cunha, ${ }^{*, a}$ Fernando César de Macedo Jr., ${ }^{a}$ Giselle A. N. Costa, ${ }^{a}$ Daniela C. Neves, ${ }^{a}$ \\ Lourdes Cardoso de Souza Neta, ${ }^{a}$ Ivo Vencato, ${ }^{b}$ José R. Sabino ${ }^{b}$ and Carlito Lariucci ${ }^{b}$
}

anstituto de Química, Universidade Federal da Bahia, Campus de Ondina, 40170-290 Salvador-BA, Brazil

${ }^{b}$ Instituto de Física, Universidade Federal de Goiás, CP 131, 74001-970 Goiânia-GO, Brazil

\begin{abstract}
Guanil-hidrazonas poli-substituídas foram sintetizadas através da reação de guanilação de tiossemicarbazonas com aminas aromáticas e alifáticas, promovida $\mathrm{HgCl}_{2}$. Este método representa o primeiro emprego de tiossemicarbazonas como componente eletrofílico em reações de síntese de guanidinas mediadas por tiófilo, onde a introdução de cada substituinte dos nitrogênios das guanil-hidrazonas ocorreu de forma regiosseletiva. As atividades antibacteriana e antifúngica foram avaliadas e alguns derivados mostraram atividade em valores pequenos de concentração inibitória mínima e com amplo espectro de atividade. Estudou-se a estrutura cristalina de duas guanil-hidrazonas, determinando-se suas configurações e, as únicas interações relevantes observadas foram intermoleculares do tipo $\mathrm{N}-\mathrm{H}$...N e $\mathrm{C}-\mathrm{H} . . . \mathrm{N}$.
\end{abstract}

Thiosemicarbazones were employed for the first time as electrophiles in the guanylation reaction promoted by $\mathrm{HgCl}_{2}$, affording polysubstituted guanylhydrazones, with regioselective introduction of each nitrogen substituent. The antibacterial and antifungal activities of guanylhydrazones were evaluated by determination of minimal inhibitory concentrations. Some of them exhibited very low minimal inhibitory concentrations (MIC) and broad-spectrum activities. The configurations of two guanylhydrazones were assigned by $\mathrm{X}$-ray analysis that also revealed intramolecular interactions of the type $\mathrm{N}-\mathrm{H}$.... $\mathrm{N}$ and $\mathrm{C}-\mathrm{H}$...N.

Keywords: thiosemicarbazones, guanylhydrazones, guanidines

\section{Introduction}

Due to its large spectrum of biological activity the guanidine functional group has been intensively studied as a synthetic goal. ${ }^{1}$ As a result of these efforts, a diversity of methods, both in solution ${ }^{2}$ and in the solid phase ${ }^{3}$ have been developed. In the first case, a particularly interesting approach involves the utilization of inorganic thiophiles, such as $\mathrm{HgCl}_{2}$, as promoters of thioureas guanylation. ${ }^{4}$

From the structural point of view, guanylhydrazones can be envisioned as aldimine-guanidine derivatives. In addition, guanylhydrazones are compounds of exceptional biological importance, due to activities such as cardiotonic, ${ }^{5}$ antitumoral, ${ }^{6}$ antibacterial ${ }^{7}$ and trypanocidal agents. ${ }^{8}$ Despite these important pharmacological and biological properties, the available synthetic routes to guanylhydrazones are rather limited to structural modifications. ${ }^{5-8}$ The most successful

\footnotetext{
*e-mail: silviodc@ufba.br
}

route to this class of compounds is restricted to the reaction of oxo compounds with aminoguanidine, although only nitrogen-unsubstituted guanylhydrazones can be prepared by this method, affording structural variation only at the aldimine moiety. Moreover, the absence of selectivity in the introduction of alkyl or acyl substituents on the nitrogens of the guanidine moiety of the guanylhydrazones is a serious drawback for obtaining a library of $\mathrm{N}$-substituted guanylhydrazones by this route.

Recently, we demonstrated that $\mathrm{N}$-benzoylthioureas are easily converted to acylguanidines using $\mathrm{HgCl}_{2}$, being a versatile starting material for densely substituted guanidines containing electronically neutral as well as electron withdrawing and electron releasing groups. We also described $\mathrm{N}$-iminopyridinium ylide as the nucleophilic component in this reaction. ${ }^{9}$ These results prompted us to explore the scope of these protocols by the utilization of thiosemicarbazones as substrates for the guanylation reaction, which should afford polysubstituted guanylhydrazones. 
While a broad spectrum of thioureas have been investigated in guanylation methodologies promoted by inorganic thiophiles, the use of more functionalized derivatives is limited. To the best of our knowledge, there is no literature precedent for thiosemicarbazone as the eletrophilic component in the guanylation reaction. Thus, we envisaged this strategy as a convenient route to guanylhydrazones. Moreover, the above mentioned limitation in the synthesis of polysubstituted guanylhydrazones by the traditional methods can be overcome, in principle, by the controlled preparation of a substituted thiosemicarbazones followed by their guanylation reaction with an appropriate amine.

Herein we disclose our results concerning the synthesis of new guanylhydrazones by guanylation of thiosemicarbazones, using $\mathrm{HgCl}_{2}$ as thiophile. The antibacterial and antifungal activities of all obtained compounds, as well as a structural study of two of them by X-ray analysis, are also described.

\section{Results and Discussion}

To amplify the scope of the guanylation reaction by the utilization of polysubstituted thiosemicarbazones as substrates, a representative set of such compounds was required. Thus, the derivatives 1a-g were obtained in good overall yields from treatment of phenyl isothiocyanate with hydrazine followed by condensation of the thiosemicarbazide with a series of carbonyl compounds according to literature procedures (Scheme 1). ${ }^{10,11}$

Thiosemicarbazones can be envisioned as a thiourea with an additional nitrogen atom. They are interesting starting materials for the evaluation of electronic effects in guanylation reactions because the additional nitrogen atom is a point for structural diversification.

Thus, with a representative set of thiosemicarbazones in hand, we turned our attention to the guanylation reaction. The utilization of $\mathrm{HgCl}_{2}$ as a thiophile promoted the guanylation of thiosemicarbazones 1a-g with cyclohexylamine, giving the corresponding guanylhydrazones (Table 1). In general, the electronic nature of the aryl group substituent in the aldimine moiety of $\mathbf{1}$ could vary from electron withdrawing groups, as in 1c, $1 \mathbf{e}$ and $\mathbf{1 g}$, to electron releasing groups as in $\mathbf{1 d}$ and $\mathbf{1 j}$. All reactions were tentatively submitted to optimization under heat $\left(70-75^{\circ} \mathrm{C}\right)$. Although only guanylhydrazone $\mathbf{2 g}$ was obtained with a significant yield improvement, the reaction time was reduced for all compounds (Table 1).

Table 1. Isolated guanylhydrazones yields

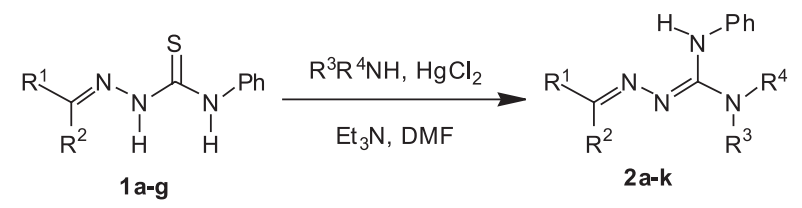

\begin{tabular}{lcccc}
\hline 2 & Thiosemicarbazone & Amine & \multicolumn{2}{c}{ Yield (\%) } \\
& $\mathrm{R}^{1}, \mathrm{R}^{2}$ & $\mathrm{R}^{3}, \mathrm{R}^{4}$ & $\mathrm{rt}, 24 \mathrm{~h}$ & $70{ }^{\circ} \mathrm{C}, 12 \mathrm{~h}$ \\
\hline $\mathbf{2 a}$ & $\mathrm{Ph}, \mathrm{CH}_{3}$ & $\mathrm{c}-\mathrm{C}_{6} \mathrm{H}_{11}, \mathrm{H}$ & 73 & 68 \\
$\mathbf{2 b}$ & $\mathrm{Ph}, \mathrm{H}$ & $\mathrm{c}-\mathrm{C}_{6} \mathrm{H}_{11}, \mathrm{H}$ & 81 & 65 \\
$\mathbf{2 c}$ & $p-\mathrm{NO}_{2} \mathrm{Ph}, \mathrm{H}$ & $\mathrm{c}-\mathrm{C}_{6} \mathrm{H}_{11}, \mathrm{H}$ & 66 & 62 \\
$\mathbf{2 d}$ & $p-\mathrm{MeOPh}, \mathrm{H}$ & $\mathrm{c}-\mathrm{C}_{6} \mathrm{H}_{11}, \mathrm{H}$ & 45 & 36 \\
$\mathbf{2 e}$ & $p-\mathrm{ClPh}, \mathrm{H}$ & $\mathrm{c}-\mathrm{C}_{6} \mathrm{H}_{11}, \mathrm{H}$ & 33 & 40 \\
$\mathbf{2 f}$ & $o-\mathrm{HOPh}, \mathrm{H}$ & $\mathrm{c}-\mathrm{C}_{6} \mathrm{H}_{11}, \mathrm{H}$ & 60 & 62 \\
$\mathbf{2 g}$ & $\mathrm{Furan}-2-\mathrm{yl}, \mathrm{H}$ & $\mathrm{c}-\mathrm{C}_{6} \mathrm{H}_{11}, \mathrm{H}$ & 26 & 67 \\
$\mathbf{2 h}$ & $\mathrm{Ph}, \mathrm{H}$ & $i-\mathrm{Pr}_{1} \mathrm{H}$ & 62 & - \\
$\mathbf{2 i}$ & $\mathrm{Ph}, \mathrm{H}$ & $\mathrm{Bn}_{1} \mathrm{H}$ & 65 & - \\
$\mathbf{2 j}$ & $\mathrm{Ph}, \mathrm{H}$ & $\mathrm{Phenylethyl}_{1} \mathrm{H}$ & 23 & - \\
$\mathbf{2 k}$ & $\mathrm{Ph}, \mathrm{H}$ & $\mathrm{CH}_{2} \mathrm{CH}_{2} \mathrm{OCH} \mathrm{CH}_{2}$ & 61 & - \\
\hline
\end{tabular}

To verify the scope of the nucleophilic amine, thiosemicarbazone $\mathbf{1 b}$ was submitted to the guanylation reaction with other amines. Both primary and secondary amines were evaluated, and the corresponding guanylhydrazones $\mathbf{2 h - k}$ were obtained in moderate to satisfactory yields (except for $\mathbf{2 e}$ and $\mathbf{2} \mathbf{j}$, Table $\mathbf{1}$ ).

The structures of two polysubstituted guanylhydrazones, 2a and $\mathbf{2 c}$, were established by analysis of their spectroscopic data and unambiguously confirmed by X-ray crystallography. Thus, the $1 E, 3 Z$ configuration of the double bonds in $\mathbf{2 a}$ and $\mathbf{2 c}$ was confirmed, as can be seen in their ORTEP ${ }^{12}$ representation (Figure 1). For 2a, an intramolecular hydrogen bond between atoms N1-H1...N5 [2.561(2) $\AA$, 112(2) $\left.{ }^{\circ}\right]$ stabilizes the planarity through the conjugation of atoms N1-C2-N4-N5 [dihedral angle $-1.4(2)^{\circ}$ ]. This planarity is reinforced by the occurrence of two weak interactions involving atoms C7H7A...N4 [2.723(3) $\left.\AA, 100(2)^{\circ}\right]$ and C20-H20...N4 [2.807(2) $\left.\AA, 100(1)^{\circ}\right]$. For $2 \mathbf{c}$, an intramolecular hydrogen bond between

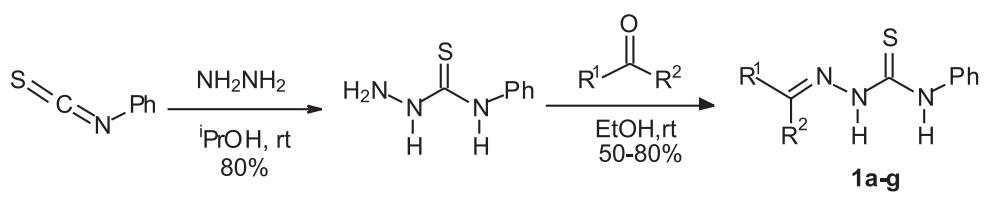

Scheme 1. 

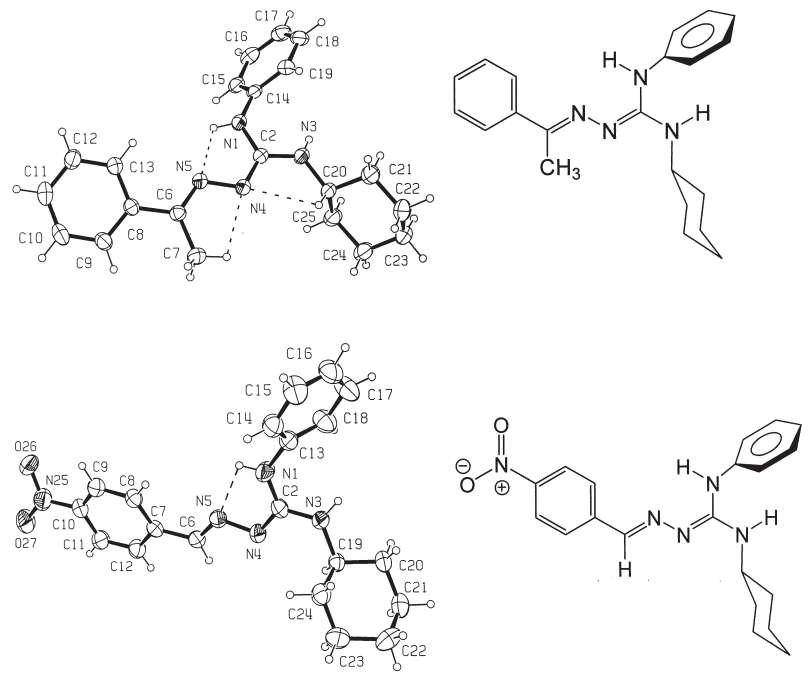

Figure 1. Crystal structures of 2a (top) and 2c (bottom). Displacement ellipsoids are drawn at the $30 \%$ probability level and $\mathrm{H}$ atoms are shown as spheres of arbitrary radii. The intramolecular H-bonds are shown with dashed lines.

atoms N1-H1...N5 [2.528(9) $\left.\AA, 1^{\circ}{ }^{\circ}\right]$ was observed. The structures of all other guanylhydrazones were determined by comparison of their spectroscopic data (IR and NMR), which were consistently correlated with those of $\mathbf{2 a}$ and $\mathbf{2 c}$. Despite the possibility of forming several geometric isomers of the guanylhydrazones $\mathbf{2}$, only one isomer was observed for all the prepared guanylhydrazones.

Mechanistically, two reaction pathways may be postulated for the formation of guanylhydrazones (Scheme 2), both of which should involve an initial activated species (3) formed by complexation of thiosemicabazones with $\mathrm{Hg}^{2+}$. In the absence of $\mathrm{HgCl}_{2}$ no reaction occurs and the reagents were fully recovered. In pathway A, 3 suffers desulfurization forming a carbodiimide intermediate (4), which is trapped

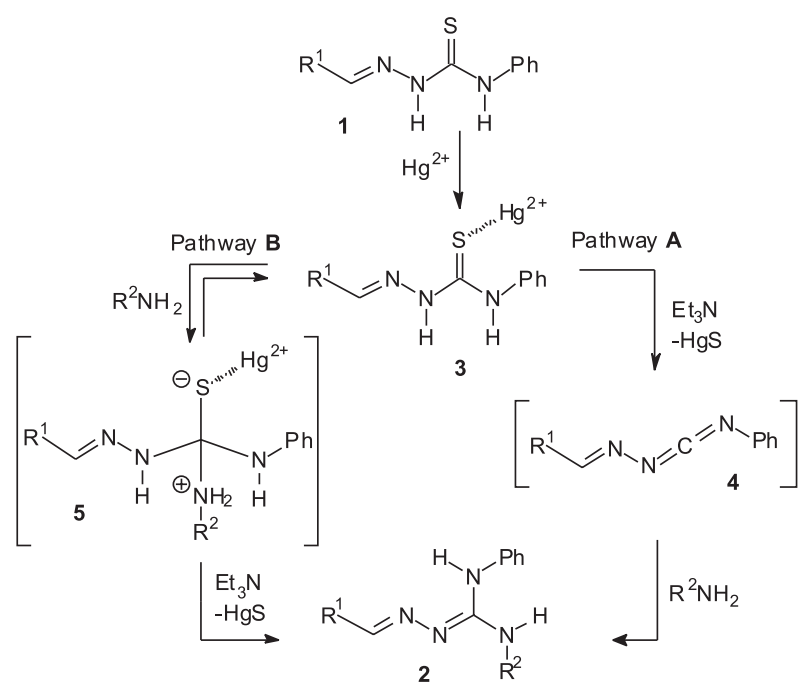

Scheme 2. by the nucleophilic amine affording 2 . Alternatively, species $\mathbf{3}$ may suffer an addition-elimination reaction via the intermediate $\mathbf{5}$, affording the guanylhydrazones. Both mechanistic proposals have been invoked in the literature concerning guanidine synthesis from thioureas. ${ }^{13}$

The antimicrobial activities of the synthesized guanylhydrazones were evaluated in bioassays involving Gram-positive (entries 1-4, Table 2) and Gram-negative (entries 5-7) bacteria as well as fungi (entries 8-10). As can be verified in the shadowed region of Table 2 , all the compounds showed antimicrobial activity in the tested concentrations. In some cases, the minimal inhibitory concentrations (MIC) were similar (2b and $\mathbf{2 d}$ ) or even lower (2b) than that recorded for the positive control. Guanylhydrazones $\mathbf{2 b}-\mathbf{2 g}$ showed a clear selectivity against Gram-positive bacteria. Structurally, while the change of the phenyl ring to the furanyl group in $2 \mathrm{~g}$ leads to an overall decrease in the activity levels, the substitution of the aldimine hydrogen by a methyl group abolishes completely the antibacterial activity, as can be observed by comparison of $\mathbf{2 a}$ with $\mathbf{2 b}$. Antifungal activity was observed for compounds $\mathbf{2 a - g}$, with $\mathbf{2 b}$ being the most active substance.

The antimicrobial activity of the guanylhydrazones herein reported is a relevant result since the emergence of resistance to the major classes of antibiotics is recognized as a serious health concern. ${ }^{14}$ Particularly, the emergence of multidrug-resistant strains of Gram-positive bacterial pathogens is a problem of ever increasing significance. Organisms including methicillin-resistant Staphylococcus aureus and Staphylococcus epidermidis, vancomycin-resistant enterococci, and penicillin- and cephalosporin-resistant streptococci are continually challenging scientists, physicians and patients..$^{14,15}$ Therefore, the search for antibacterial agents will always remain an important and challenging task.

In summary, we demonstrated for the first time that thiosemicarbazones are suitable substrates for guanylation reactions promoted by $\mathrm{HgCl}_{2}$. This new route to guanylhydrazones is a versatile protocol since it permits access to adducts with highly variable substitution patterns at the nitrogen atoms and a regioselective introduction of each substituent. Since the experimental conditions are simple, inexpensive and mild, we believe that our methodology would be useful for the preparation of complex bioactive derivatives. In addition, most of the aromatic guanylhydrazones prepared during this investigation demonstrated significant antibacterial and antifungal activities. These results suggest that guanylhydrazones are promising compounds for the development of antimicrobial drugs. In particular, $2 \mathbf{b}$ exhibited very low MIC values and a broad-spectrum of activity that should be relevant from a clinical perspective. Further synthesis optimizations and detailed SAR studies are currently under investigation and will be reported in due course. 
Table 2. Minimal inhibitory concentration (MIC) of guanylhydrazones

\begin{tabular}{|c|c|c|c|c|c|c|c|c|c|c|c|c|c|}
\hline \multirow{2}{*}{ Entry } & \multirow{2}{*}{ Microorganisms $\#$} & \multicolumn{12}{|c|}{ Guanylhydrazones (MIC; $\mu \mathrm{g} / \mathrm{mL}$ ) } \\
\hline & & $2 \mathbf{a}$ & $2 b$ & $2 c$ & 2d & $2 \mathbf{e}$ & $2 f$ & $2 \mathrm{~g}$ & $2 \mathrm{~h}$ & $2 \mathbf{i}$ & $2 \mathbf{j}$ & $2 \mathbf{k}$ & $\mathrm{PC}^{*}$ \\
\hline 1 & B. subtilis & $>100$ & 6.3 & 100 & 12.5 & 25 & 12.5 & 100 & 25 & 25 & 50 & $>100$ & 6.3 \\
\hline 2 & S. aureus & $>100$ & 6.3 & 100 & 50 & 100 & 100 & 100 & 25 & 50 & 50 & $>100$ & 6.3 \\
\hline 3 & M. luteus & $>100$ & 6.3 & 50 & 12.5 & 50 & 25 & 100 & 12.5 & 12.5 & 6.3 & $>100$ & 0.78 \\
\hline 4 & S. mutans & $>100$ & 6.3 & 100 & $\mathbf{5 0}$ & 100 & $\mathbf{5 0}$ & 100 & 25 & 50 & 50 & $>100$ & 6.3 \\
\hline 5 & S. choleaesuís & $>100$ & 25 & $>100$ & $>100$ & $>100$ & $>100$ & $>100$ & $>100$ & $>100$ & $>100$ & $>100$ & 6.3 \\
\hline 6 & E. coli & $>100$ & 25 & $>100$ & $>100$ & $>100$ & $>100$ & $>100$ & $>100$ & $>100$ & $>100$ & $>100$ & 3.1 \\
\hline 7 & P. aeruginosa & $>100$ & $>100$ & $>100$ & $>100$ & $>100$ & $>100$ & $>100$ & 25 & $\mathbf{5 0}$ & $>100$ & $>100$ & 100 \\
\hline 8 & C. albicans & 100 & 12.5 & 100 & 25 & 50 & $>100$ & $>100$ & $>100$ & $>100$ & $>100$ & $>100$ & 6.3 \\
\hline 9 & A. Níger & 100 & 3.1 & 100 & 100 & 100 & 100 & $>100$ & $>100$ & $>100$ & $>100$ & $>100$ & 12.5 \\
\hline 10 & C. cladosporioides & 100 & 3.1 & 100 & 100 & 100 & 100 & $>100$ & $>100$ & $>100$ & 100 & $>100$ & 6.3 \\
\hline
\end{tabular}

${ }^{\#}$ B. subtilis ATCC 6633, S. aureus ATCC6638, M. luteus ATCC10240, S. mutans ATCC 24175, S. choleaesuis TCC 14028, E. coli ATCC $94863, P$. aeruginosa, C. albicans ATCC 18804, A. niger ATCC 16404, C. cladosporioides IMI178517; *PC: Positive Control (chloramphenicol for bacteria and ciclopirox olamin for fungi).

\section{Experimental}

Melting points were determined on a Microquímica MQAPF 301 hot plate apparatus and are uncorrected. Infrared spectra were recorded as $\mathrm{KBr}$ discs on a FT-IR Bomem MB100 instrument. NMR spectra were obtained for ${ }^{1} \mathrm{H}$ at $300 \mathrm{MHz}$ and for ${ }^{13} \mathrm{C}$ at $75 \mathrm{MHz}$ using a Varian Gemini 300 spectrometer. Chemical shifts are reported in ppm using TMS as internal reference. Coupling constants $(J)$ are in hertz $(\mathrm{Hz})$. The single crystal X-ray diffraction data collection was carried out on a Nonius CAD-4 diffractometer. Thiosemicarbazones 1a-g were prepared according to known procedures. ${ }^{10}$

\section{General synthetic procedure}

To a solution of thiosemicarbazone $(0.5 \mathrm{mmol})$ in DMF $(3 \mathrm{~mL})$, cyclohexylamine $(0.5 \mathrm{mmol}), \mathrm{Et}_{3} \mathrm{~N}(1.0 \mathrm{mmol})$ and then $\mathrm{HgCl}_{2}(0.5 \mathrm{mmol})$ were added under magnetic stirring. The suspension became dark after a few minutes and was left stirring at room temperature (or heated at $70-75^{\circ} \mathrm{C}$ in an oil bath) while the progress of the reaction was monitored by TLC. When the thiosemicarbazone was consumed, $\mathrm{CH}_{2} \mathrm{Cl}_{2}$ $(10 \mathrm{~mL})$ was added and the suspension was filtered through a pad of Celite. The solvents were removed under reduced pressure and the residue was purified as indicated in each case.

CAUTION: $\mathrm{HgCl}_{2}$ is very toxic and both the reagent and the crude product must be manipulated carefully. Although the by-product of the reaction, $\mathrm{HgS}$, is a highly water insoluble, the solid residue retained in the short celite column must be disposed of in a suitable flask.
The appropriate disposal of celite and $\mathrm{SiO}_{2}$ used in the purification process must also be considered.

(2Z)-2-(1-Phenylethylideneamino)(cyclohexyl)-3phenylguanidine (2a)

Yellowish solid, mp 111-113 ${ }^{\circ} \mathrm{C}$ (recrystallized from ethanol); IR (KBr) $v_{\text {max }} / \mathrm{cm}^{-1}: 3413,3357,2923,2852,1595$, 1534, 1383, 757 and 706; ${ }^{1} \mathrm{H}$ NMR (300 MHz; $\left.\mathrm{CDCl}_{3}\right) \delta$ 1.1-1.4 (5 H, m, $\left.\mathrm{CH}_{2}\right), 1.6-1.8\left(3 \mathrm{H}, \mathrm{m}, \mathrm{CH}_{2}\right), 2.1(2 \mathrm{H}, \mathrm{m}$, $\left.\mathrm{CH}_{2}\right), 2.48\left(3 \mathrm{H}, \mathrm{s}, \mathrm{CH}_{3}\right), 3.91(1 \mathrm{H}, \mathrm{m}, \mathrm{NCH}), 4.04(1 \mathrm{H}, \mathrm{br}$ s, NH), 7.05-7.40 (8 H, m, Ph), 7.79 (2 H, d, J 6.9, Ph), and 8.04 (1 H, br s, NH); ${ }^{13} \mathrm{C}$ NMR (75.46 MHz; $\left.\mathrm{CDCl}_{3}\right) \delta 14.2$ $\left(1 \mathrm{CH}_{3}\right), 24.9\left(2 \mathrm{CH}_{2}\right), 25.8\left(1 \mathrm{CH}_{2}\right), 33.3\left(2 \mathrm{CH}_{2}\right), 49.4(1 \mathrm{CH})$, $123.9(2 \mathrm{CH}), 124.7(1 \mathrm{CH}), 126.0(2 \mathrm{CH}), 127.9(1 \mathrm{CH}), 128.0$ $(2 \mathrm{CH}), 129.6(2 \mathrm{CH}), 138.6(1 \mathrm{C}), 140.2$ (1C), $153.2(1 \mathrm{C})$, and 153.9 (1C). Anal. found C, 75.22; H, 7.98; N, 16.23; $\mathrm{C}_{21} \mathrm{H}_{26} \mathrm{~N}_{4}$ requires $\mathrm{C}, 75.41 ; \mathrm{H}, 7.84 ; \mathrm{N}, 16.75 \%$.

\section{(2Z)-2-(Benzylideneamino)(cyclohexyl)-3-phenylguanidine} (2b)

White solid, mp $119-121{ }^{\circ} \mathrm{C}$ (recrystallized from ethanol); IR (KBr) $v_{\max } / \mathrm{cm}^{-1}: 3197,3067,3041,2934,2856$, 1741, 1600, 1567, 1537, 1496, 765, and 394; ${ }^{1} \mathrm{H}$ NMR (300 $\left.\mathrm{MHz}, \mathrm{CDCl}_{3}\right) \delta 1.14-1.40\left(5 \mathrm{H}, \mathrm{m}, \mathrm{CH}_{2}\right), 1.58-1.66(3 \mathrm{H}$, $\left.\mathrm{m}, \mathrm{CH}_{2}\right), 2.03$ (2 H, br s, $\left.\mathrm{CH}_{2}\right), 3.87$ (1 H, m, NCH), 4.11 (1 H, br s, NH), 7.19-7.27 (3 H, m, Ph), 7.30-7.38 (3 H, m, $\mathrm{Ph}), 7.37$ (2 H, overlap, d, $J$ 6.6, Ph), 7.69 (2 H, d, $J$ 6.6, $\mathrm{Ph})$, and $8.34(1 \mathrm{H}, \mathrm{s}, \mathrm{CH}) ;{ }^{13} \mathrm{C} \mathrm{NMR}\left(75.46 \mathrm{MHz}, \mathrm{CDCl}_{3}\right)$ $\delta 24.7\left(2 \mathrm{CH}_{2}\right), 25.6\left(1 \mathrm{CH}_{2}\right), 33.6\left(2 \mathrm{CH}_{2}\right), 49.1(1 \mathrm{CH}), 124.2$ $(2 \mathrm{CH}), 125.1(1 \mathrm{CH}), 126.9(2 \mathrm{CH}), 128.4(2 \mathrm{CH}), 128.7$ $(1 \mathrm{CH}), 129.7$ (2CH), $136.1(1 \mathrm{C}), 138.2(1 \mathrm{C}), 148.3(1 \mathrm{CH})$ and 155.1 (1C). Anal. found C, 74.78; H 7.32; N, 17.28; $\mathrm{C}_{20} \mathrm{H}_{24} \mathrm{~N}_{4}$ requires $\mathrm{C}, 74.97 ; \mathrm{H}, 7.55 ; \mathrm{N}, 17.48$. 
(2Z)-2-(4-Nitrobenzylideneamino)(cyclohexyl)-3phenylguanidine (2c)

Yellow solid, mp $167-169{ }^{\circ} \mathrm{C}$ (recrystallized from ethanol); IR (KBr) $v_{\max } / \mathrm{cm}^{-1}: 3395,3339,2934,2847$, 1615, 1589, 1544, 1510, 1334, 1089, 751, 721 and 687. ${ }^{1} \mathrm{H}$ NMR $\left(300 \mathrm{MHz}, \mathrm{CDCl}_{3}\right) \delta 1.10-1.45\left(5 \mathrm{H}, \mathrm{m}, \mathrm{CH}_{2}\right)$, 1.55-1.80 (3 H, m, $\left.\mathrm{CH}_{2}\right), 2.02\left(2 \mathrm{H}, \mathrm{m}, \mathrm{CH}_{2}\right), 3.89(1 \mathrm{H}$, $\mathrm{m}, \mathrm{NCH}), 4.38(1 \mathrm{H}$, br s, NH), $7.25(2 \mathrm{H}, \mathrm{d}, J 7.5, \mathrm{Ph})$, $7.25(1 \mathrm{H}$, overlap, $\mathrm{Ph}), 7.41(2 \mathrm{H}, \mathrm{m}, \mathrm{Ph}), 7.79(2 \mathrm{H}, \mathrm{d}, J$ 8.9, Ph), $8.19\left(2 \mathrm{H}, \mathrm{d}, J\right.$ 8.9, Ph) and $8.37(1 \mathrm{H}, \mathrm{s}, \mathrm{CH}) ;{ }^{13} \mathrm{C}$ NMR (75.46 MHz, $\left.\mathrm{CDCl}_{3}\right) \delta 24.7\left(2 \mathrm{CH}_{2}\right), 25.5\left(1 \mathrm{CH}_{2}\right)$, $33.5\left(2 \mathrm{CH}_{2}\right), 49.3(1 \mathrm{CH}), 123.9(4 \mathrm{CH}), 124.6(1 \mathrm{CH})$, $126.8(2 \mathrm{CH}), 129.8(2 \mathrm{CH}), 137.4(1 \mathrm{C}), 142.7(1 \mathrm{C}), 144.8$ $(1 \mathrm{CH}), 147.2$ (1C), 156.1 (1C). Anal. found C, 65.72; H, 6.62; N, 19.21; $\mathrm{C}_{20} \mathrm{H}_{23} \mathrm{~N}_{5} \mathrm{O}_{2}$ requires $\mathrm{C}, 65.74 ; \mathrm{H}, 6.34$; $\mathrm{N}, 19.16 \%$.

(2Z)-2-(4-Methoxybenzylideneamino)(cyclohexyl)-3phenylguanidine (2d)

Brownish oil. Purified through silica-gel column chromatography (hexane/ethyl acetate). IR (film) $v_{\max }$ ' $\mathrm{cm}^{-1}$ : 3428, 3341, 3067, 3037, 2934, 2855, 1611, 1585, 1562, 1531, 1513, 1250, 1167, 1030, 828, 753 and 691. ${ }^{1} \mathrm{H}$ NMR (300 MHz, $\left.\mathrm{CDCl}_{3}\right) \delta 1.10-1.45\left(5 \mathrm{H}, \mathrm{m}, \mathrm{CH}_{2}\right)$, 1.50-1.75 (3 H, m, $\left.\mathrm{CH}_{2}\right), 2.00\left(2 \mathrm{H}, \mathrm{m}, \mathrm{CH}_{2}\right), 3.82(3 \mathrm{H}, \mathrm{s}$, $\left.\mathrm{CH}_{3}\right), 3.82(1 \mathrm{H}, \mathrm{m}, \mathrm{NCH}), 6.89(2 \mathrm{H}, \mathrm{d}, J 8.6, \mathrm{Ph}), 7.18-$ $7.26(3 \mathrm{H}, \mathrm{m}, \mathrm{Ph}), 7.35-7.40(2 \mathrm{H}, \mathrm{m}, \mathrm{Ph}), 7.62(2 \mathrm{H}, \mathrm{d}$, $J$ 8.6, Ph) and $8.34(1 \mathrm{H}, \mathrm{s}, \mathrm{CH}) .{ }^{13} \mathrm{C}$ NMR $(75.46 \mathrm{MHz}$, $\left.\mathrm{CDCl}_{3}\right) \delta 24.6\left(2 \mathrm{CH}_{2}\right), 25.3\left(1 \mathrm{CH}_{2}\right), 33.3\left(2 \mathrm{CH}_{2}\right), 50.4$ $(1 \mathrm{CH}), 55.0(1 \mathrm{CH} 3), 114.0(2 \mathrm{CH}), 125.5(1 \mathrm{CH}), 127.3$ $(2 \mathrm{CH}), 128.9(2 \mathrm{CH}), 130.2(2 \mathrm{CH}), 133.8$ (1C), $149.4(1 \mathrm{C})$, $154.3(1 \mathrm{C}), 157.7(1 \mathrm{CH})$ and $159.8(1 \mathrm{C})$; Anal. found $\mathrm{C}$, 71.73; H, 7.88; N, 15.84; $\mathrm{C}_{21} \mathrm{H}_{26} \mathrm{~N}_{4} \mathrm{O}$ requires C, 71.97; $\mathrm{H}, 7.48 ; \mathrm{N}, 15.99 \%$.

(2Z)-2-(4-Chlorobenzylideneamino)(cyclohexyl)-3phenylguanidine (2e)

Yellowish solid, mp $98-105{ }^{\circ} \mathrm{C}$ (recrystallized from ethanol); IR (KBr) $v_{\max } / \mathrm{cm}^{-1}: 3415,3330,3069,3039$, 2927, 2856, 1615, 1574, 1552, 1530, 1497, 1381, 1239, 1086 and 754. ${ }^{1} \mathrm{H}$ NMR (300 MHz, $\left.\mathrm{CDCl}_{3}\right) \delta 1.12-1.43$ (5 $\left.\mathrm{H}, \mathrm{m}, \mathrm{CH}_{2}\right), 1.57-1.69\left(3 \mathrm{H}, \mathrm{m}, \mathrm{CH}_{2}\right), 2.01\left(2 \mathrm{H}, \mathrm{m}, \mathrm{CH}_{2}\right)$, $3.85(1 \mathrm{H}, \mathrm{m}, \mathrm{NCH}), 4.11(1 \mathrm{H}$, br q, J 7.1, NH), 7.21 (3 $\mathrm{H}$, br d, J 7.2, Ph), 7.30 (2 H, d, J 8.4, Ph), 7.36 (2 H, br t, $J$ 7.2, Ph), $7.61(2 \mathrm{H}, \mathrm{d}, J$ 8.4, $\mathrm{Ph})$ and $8.28(1 \mathrm{H}, \mathrm{s}, \mathrm{CH})$; ${ }^{13} \mathrm{C} \mathrm{NMR}\left(75.46 \mathrm{MHz}, \mathrm{CDCl}_{3}\right) \delta 24.7\left(2 \mathrm{CH}_{2}\right), 25.6\left(1 \mathrm{CH}_{2}\right)$, $33.5\left(2 \mathrm{CH}_{2}\right), 49.1(1 \mathrm{CH}), 124.2(2 \mathrm{CH}), 125.2(1 \mathrm{CH}), 127.9$ $(2 \mathrm{CH}), 128.6(2 \mathrm{CH}), 129.6(2 \mathrm{CH}), 134.2(1 \mathrm{C}), 134.7(1 \mathrm{C})$, $138.0(1 \mathrm{C}), 146.8(1 \mathrm{CH})$ and $155.3(1 \mathrm{C})$. Anal. found $\mathrm{C}$, 67.58; H, 6.50; N, 15.44; $\mathrm{C}_{20} \mathrm{H}_{23} \mathrm{ClN}_{4}$ requires $\mathrm{C}$, 67.69; $\mathrm{H}, 6.53 ; \mathrm{N}, 15.79 \%$.
(2Z)-2-(2-Hydroxybenzylideneamino)(cyclohexyl)-3phenylguanidine $(2 f)$

Brownish oil. Purified through silica-gel column chromatography (hexane/ethyl acetate). IR (film) $v_{\max } / \mathrm{cm}^{-1}$ : 3421, 3337, 3056, 2934, 2858, 1615, 1570, 1528, 1498, $1452,1400,1330,1308,1292,1265,1247,1152,753,730$ and 688. ${ }^{1} \mathrm{H} \mathrm{NMR}\left(300 \mathrm{MHz}, \mathrm{CDCl}_{3}\right) \delta 1.15-1.42(5 \mathrm{H}, \mathrm{m}$, $\left.\mathrm{CH}_{2}\right), 1.57-1.71\left(3 \mathrm{H}, \mathrm{m}, \mathrm{CH}_{2}\right), 2.02\left(2 \mathrm{H}, \mathrm{m}, \mathrm{CH}_{2}\right), 3.76$ $(1 \mathrm{H}, \mathrm{m}, \mathrm{NCH}), 4.11(1 \mathrm{H}$, br q, J 7.1, NH), $6.88(1 \mathrm{H}, \mathrm{dt}$, $J$ 7.4, 1.1, Ph), $6.93(1 \mathrm{H}$, br d, J 7.9, Ph), 7.18-7.25 (3 H, overlap, Ph), 7.22 (2 H, d, J 7.4, Ph), 7.36 (2 H, br t, J 7.8, $\mathrm{Ph})$ and $8.41(1 \mathrm{H}, \mathrm{s}, \mathrm{CH}) ;{ }^{13} \mathrm{C} \mathrm{NMR}\left(75.46 \mathrm{MHz}, \mathrm{CDCl}_{3}\right) \delta$ $24.7\left(2 \mathrm{CH}_{2}\right), 25.5\left(1 \mathrm{CH}_{2}\right), 33.5\left(2 \mathrm{CH}_{2}\right), 49.6(1 \mathrm{CH}), 116.1$ $(1 \mathrm{CH}), 119.39(1 \mathrm{CH}), 119.5(1 \mathrm{C}), 124.0(2 \mathrm{CH}), 125.5$ $(2 \mathrm{CH}), 129.6(1 \mathrm{CH}), 130.0(1 \mathrm{CH}), 130.4(\mathrm{CH}), 138.0(1 \mathrm{C})$, $152.8(1 \mathrm{CH}), 152.8(1 \mathrm{C})$ and $158.0(1 \mathrm{C})$. Anal. found $\mathrm{C}$, $71.60 ; \mathrm{H}, 7.22 ; \mathrm{N}, 16.25 ; \mathrm{C}_{20} \mathrm{H}_{24} \mathrm{~N}_{4} \mathrm{O}$ requires $\mathrm{C}, 71.40 ; \mathrm{H}$, $7.19 ; \mathrm{N}, 16.65 \%$.

(2E)-2-((Furan-2-yl)methyleneamino $)($ cyclohexyl)-3phenylguanidine $(2 \mathrm{~g})$

Yellowish solid, mp $115-118^{\circ} \mathrm{C}$. Purified through silicagel column chromatography (hexane/ethyl acetate). IR ( $\mathrm{KBr}$ ) $v_{\text {max }} / \mathrm{cm}^{-1}: 3384,2928,2851,1626,1525,742$ and $689 ;{ }^{1} \mathrm{H}$ NMR (300 MHz, $\left.\mathrm{CDCl}_{3}\right) \delta 1.10-1.39\left(5 \mathrm{H}, \mathrm{m}, \mathrm{CH}_{2}\right), 1.57-$ $1.69\left(3 \mathrm{H}, \mathrm{m}, \mathrm{CH}_{2}\right), 2.00-2.10\left(2 \mathrm{H}, \mathrm{m}, \mathrm{CH}_{2}\right), 3.82(1 \mathrm{H}, \mathrm{m}$, $\mathrm{NCH}), 4.10(1 \mathrm{H}$, br s, NH), $6.43(1 \mathrm{H}, \mathrm{dd}, J 3.3,1.8, \mathrm{CH})$, $6.57(1 \mathrm{H}, \mathrm{d}, J 3.3, \mathrm{CH}), 7.19$ (2 H, d, J 7.4, Ph), $7.19(1 \mathrm{H}$, overlap, $\mathrm{Ph}), 7.36(2 \mathrm{H}, \mathrm{t}, 7.4, \mathrm{Ph}), 7.44(1 \mathrm{H}, \mathrm{s}, \mathrm{CH})$ and $8.18(1 \mathrm{H}, \mathrm{s}, \mathrm{CH}) ;{ }^{13} \mathrm{C} \mathrm{NMR}\left(75.46 \mathrm{MHz}, \mathrm{CDCl}_{3}\right) \delta 24.7$ $\left(2 \mathrm{CH}_{2}\right), 25.5\left(1 \mathrm{CH}_{2}\right), 33.4\left(2 \mathrm{CH}_{2}\right), 49.0(1 \mathrm{CH}), 110.4(1 \mathrm{CH})$, $111.5(1 \mathrm{CH}), 124.2(2 \mathrm{CH}), 125.0(1 \mathrm{CH}), 129.5(2 \mathrm{CH}), 137.5$ $(1 \mathrm{CH}), 137.9(1 \mathrm{C}), 143.0(1 \mathrm{CH}), 151.6(1 \mathrm{C})$ and $155.0(1 \mathrm{C})$. Anal. found $\mathrm{C}, 69.72 ; \mathrm{H}, 6.20 ; \mathrm{N}, 18.21 ; \mathrm{C}_{18} \mathrm{H}_{22} \mathrm{~N}_{4} \mathrm{O}$ requires C, 69.65; H, 7.14; N, 18.05\%.

(2E)-2-(Benzylideneamino)(isopropyl)-3-phenylguanidine (2h)

Yellowish oil. Purified through silica-gel column chromatography (hexane/ethyl acetate). IR (film) $v_{\max }$ I $\mathrm{cm}^{-1}$ : 3431, 3347, 3060, 2972, 2867, 1614, 1580, 1556, 1530, 1498, 755 and 693. ${ }^{1} \mathrm{H}$ NMR (300 MHz, $\left.\mathrm{CDCl}_{3}\right) \delta$ $1.20\left(6 \mathrm{H}, \mathrm{d}, J 6.35, \mathrm{CH}_{3}\right), 4.03$ (1 H, br s, NH), 4.17 (1 $\mathrm{H}$, hept, $J$ 6.35, CH), 7.21 (2 H, d, J 8.4, Ph), 7.29-7.41 (5 $\mathrm{H}, \mathrm{m}, \mathrm{Ph}), 7.69(2 \mathrm{H}, \mathrm{d}, 7.2, \mathrm{Ph}), 8.00(1 \mathrm{H}, \mathrm{br} \mathrm{s}, \mathrm{NH})$ and $8.35(1 \mathrm{H}, \mathrm{s}, \mathrm{CH}) ;{ }^{13} \mathrm{C}$ NMR $\left(75.46 \mathrm{MHz}, \mathrm{CDCl}_{3}\right) \delta 23.2$ $\left(2 \mathrm{CH}_{3}\right), 42.5(1 \mathrm{CH}), 124.2(2 \mathrm{CH}), 125.0(1 \mathrm{CH}), 126.9$ $(2 \mathrm{CH}), 128.4(2 \mathrm{CH}), 128.7(1 \mathrm{CH}), 129.7(2 \mathrm{CH}), 136.2$ (1C), 138.1 (1C), $148.2(1 \mathrm{CH})$ and 155.3 (1C). Anal. found C, 70.72; H, 7.20; N, 20.21; $\mathrm{C}_{17} \mathrm{H}_{20} \mathrm{~N}_{4}$ requires C, 72.83; H, $7.19 ; \mathrm{N}, 19.98 \%$. 
(2E)-Benzyl-2-(benzylideneamino)-3-phenylguanidine (2i)

Yellowish oil. Purified through silica-gel column chromatography (hexane/ethyl acetate). IR (film) $v_{\max } / \mathrm{cm}^{-1}$ : 3429, 3352, 3064, 2923, 1615, 1580, 1558, 1534, 1498, $1378,1233,755$ and $695 ;{ }^{1} \mathrm{H}$ NMR $\left(300 \mathrm{MHz}, \mathrm{CDCl}_{3}\right) \delta$ $4.40(1 \mathrm{H}, \mathrm{br} \mathrm{s}, \mathrm{NH}), 4.58\left(2 \mathrm{H}, \mathrm{s}, \mathrm{CH}_{2}\right), 7.16-7.38(13 \mathrm{H}$, $\mathrm{m}, \mathrm{Ph}), 7.71(2 \mathrm{H}, \mathrm{d}, J$ 6.6, Ph), 7.80-7.20 (1 H, br s, NH) and $8.38(1 \mathrm{H}, \mathrm{s}, \mathrm{CH}) ;{ }^{13} \mathrm{C}$ NMR $\left(75.46 \mathrm{MHz}, \mathrm{CDCl}_{3}\right) \delta$ $45.2\left(1 \mathrm{CH}_{2}\right), 124.4(2 \mathrm{CH}), 125.3(1 \mathrm{CH}), 127.0(2 \mathrm{CH})$, $127.3(1 \mathrm{CH}), 127.7(2 \mathrm{CH}), 128.5(2 \mathrm{CH}), 128.6(2 \mathrm{CH})$, $128.8(1 \mathrm{CH}), 129.7(2 \mathrm{CH}), 136.1(1 \mathrm{C}), 137.9$ (1C), 138.8 (1C), $149.1(1 \mathrm{CH})$ and $155.8(1 \mathrm{C})$. Anal. found $\mathrm{C}, 77.06$; $\mathrm{H}, 6.22 ; \mathrm{N}, 17.17 ; \mathrm{C}_{21} \mathrm{H}_{20} \mathrm{~N}_{4}$ requires $\mathrm{C}, 76.80 ; \mathrm{H}, 6.14$; $\mathrm{N}, 17.06 \%$.

\section{(2E)-2-(Benzylideneamino)(phenyl)-3-(1-phenylethyl) guanidine (2j)}

Yellowish oil. IR (film) $v_{\max } / \mathrm{cm}^{-1}: 3408,3373,3054$, 2974, 2928, 1617, 1579, 1563, 1528, 1496, 1443, 754, 700 and 689. ${ }^{1} \mathrm{H} \mathrm{NMR}\left(300 \mathrm{MHz}, \mathrm{CDCl}_{3}\right) \delta 1.52(3 \mathrm{H}, \mathrm{d}, J 6.1$, $\left.\mathrm{CH}_{3}\right), 4.78(1 \mathrm{H}$, br s, NH), $5.24(1 \mathrm{H}, \mathrm{m}, \mathrm{CH}), 7.20-7.38$ $(13 \mathrm{H}, \mathrm{m}, \mathrm{Ph}), 7.20-7.38(1 \mathrm{H}$, overlap, $\mathrm{NH}), 7.69(2 \mathrm{H}, \mathrm{d}$, $J$ 7.1, Ph) and $8.33(1 \mathrm{H}, \mathrm{s}, \mathrm{CH}) ;{ }^{13} \mathrm{C}$ NMR $(75.46 \mathrm{MHz}$, $\left.\mathrm{CDCl}_{3}\right) \delta 22.7\left(1 \mathrm{CH}_{3}\right), 49.8(1 \mathrm{CH}), 124.2(2 \mathrm{CH}), 125.3$ $(1 \mathrm{CH}), 125.7(1 \mathrm{CH}), 126.0(2 \mathrm{CH}), 126.9(2 \mathrm{CH}), 127.0$ $(1 \mathrm{CH}), 128.4(2 \mathrm{CH}), 128.8(2 \mathrm{CH}), 129.8(2 \mathrm{CH}), 136.0$ (1C), $137.9(1 \mathrm{C}), 144.0(1 \mathrm{C}), 148.9(1 \mathrm{CH})$ and $154.9(1 \mathrm{C})$. Anal. found $\mathrm{C}, 76.97 ; \mathrm{H}, 6.88 ; \mathrm{N}, 15.91 ; \mathrm{C}_{22} \mathrm{H}_{22} \mathrm{~N}_{4}$ requires C, $77.16 ; \mathrm{H}, 6.48 ; \mathrm{N}, 16.36 \%$.

(4Z)- $N$ '-(Benzylideneamino)- $N$-phenylmorpholine-4carboxamidine $(2 k)$

Yellowish oil. Purified through silica-gel column chromatography (hexane/ethyl acetate). IR (film) $\mathrm{v}_{\max } / \mathrm{cm}^{-1}$ : 3451, 3321, 2966, 2844, 1617, 1558, 1120, 756 and 691; ${ }^{1} \mathrm{H}$ NMR (300 MHz, $\left.\mathrm{CDCl}_{3}\right) \delta 3.33\left(4 \mathrm{H}, \mathrm{t}, J 4.8, \mathrm{CH}_{2}\right)$, $3.69\left(4 \mathrm{H}, \mathrm{t}, J 4.8, \mathrm{CH}_{2}\right), 7.06(1 \mathrm{H}, \mathrm{t}, J 7.2, \mathrm{Ph}), 7.21(2 \mathrm{H}$, d, $J$ 8.5, Ph), 7.29-7.39 (5 H, m, Ph), 7.68-7.71 $(2 \mathrm{H}, \mathrm{m}$, $\mathrm{Ph}), 7.82(1 \mathrm{H}, \mathrm{br} \mathrm{s}, \mathrm{NH})$ and $8.41(1 \mathrm{H}, \mathrm{s}, \mathrm{CH}) ;{ }^{13} \mathrm{C} \mathrm{NMR}$ $\left(75.46 \mathrm{MHz}, \mathrm{CDCl}_{3}\right) \delta 47.1\left(2 \mathrm{CH}_{2}\right), 66.2\left(2 \mathrm{CH}_{2}\right), 120.2$ $(2 \mathrm{CH}), 123.2(1 \mathrm{CH}), 127.3(2 \mathrm{CH}), 128.5(2 \mathrm{CH}), 129.3$ $(2 \mathrm{CH}), 129.4(1 \mathrm{CH}), 135.5(1 \mathrm{C}), 140.8(1 \mathrm{C}), 152.0(1 \mathrm{CH})$ and 158.2 (1C). Anal. found C, 69.72; H, 6.20; N, 17.91; $\mathrm{C}_{18} \mathrm{H}_{20} \mathrm{~N}_{4} \mathrm{O}$ requires $\mathrm{C}, 70.11 ; \mathrm{H}, 6.54 ; \mathrm{N}, 18.17 \%$.

\section{Determination of minimal inhibitory concentration (MIC)}

Values are means of three experiments. The bacteria cultures used were grown for $24 \mathrm{~h}$ at $35^{\circ} \mathrm{C}$ on nutrient agar. The fungi and yeast were cultivated for $72 \mathrm{~h}$ at $26^{\circ} \mathrm{C}$ on malt extract agar and yeast malt agar respectively. The inocula for the assays were prepared by cell suspensions according to McFarland scale 0.5, except for filamentous fungi for which a modified method ${ }^{16}$ was used. A broth microdilution method was carried out to determine the MIC of the compounds against the microorganisms in sterile 96-well microplates..$^{17}$ The $20 \%$ dimethyl sulfoxide aqueous stock solutions of the compounds were transferred into the first well from which serial dilutions were performed so that concentrations ranged from 100 to $0.78 \mu \mathrm{g} \mathrm{mL}^{-1}$. Chloramphenicol and cyclopirox olamin were used as the reference drugs against bacteria and fungi respectively. Aqueous dimethyl sulfoxide (20\%) was used as negative control. The inoculum was added to all wells and the plates were incubated under the appropriate conditions. After incubation, microorganism growth was observed by the presence of turbidity in the well. MIC was defined as the lowest concentration of the substances that inhibited appearance of turbidity.

\section{Crystal structures}

(2a): $\mathrm{C}_{21} \mathrm{H}_{26} \mathrm{~N}_{4}, \mathrm{M}_{\mathrm{w}}=334.46$, monoclinic, space group $\mathrm{C} 2 / \mathrm{c}$ [nr. 15], $\mathrm{Z}=8, \mathrm{a}=32.155(9) \AA, \mathrm{b}=6.0490(9) \AA$, $c=19.916(2) \AA, \beta=98.72(2)^{\circ}, V=3829(1) \AA^{3}, d_{c}=1.160$ $\mathrm{Mg} \mathrm{m}^{-3}, \lambda(\mathrm{CuK} \alpha)=1.54180 \AA, \mu=0.54 \mathrm{~mm}^{-1}, 4129$ measured reflections, 3330 unique $\left(\mathrm{R}_{\mathrm{int}}=0.0265\right)$ of which 2958 were considered as observed with $\mathrm{I} \geq 2 \sigma(\mathrm{I})$. Final indices: $\mathrm{R}_{1}\left(\mathrm{~F}_{\mathrm{o}}\right)=0.0669$, $\mathrm{wR}_{2}\left(\mathrm{~F}^{2}\right)=0.167$ for 245 refined parameters. (2c): $\mathrm{C}_{20} \mathrm{H}_{23} \mathrm{~N}_{5} \mathrm{O}_{2}, \mathrm{M}_{\mathrm{w}}=365.43$, orthorhombic, space group $\mathrm{P}$ ca2 1 [nr. 29], $\mathrm{Z}=4, \mathrm{a}=10.495(1) \AA$, $\mathrm{b}=12.017(2) \AA, \mathrm{c}=15.583(2) \AA, \mathrm{V}=1965.3(5) \AA^{3}$, $\mathrm{d}_{\mathrm{c}}=1.235 \mathrm{Mg} \cdot \mathrm{m}^{-3}, \lambda(\mathrm{CuK} \alpha)=1.54180 \AA, \mu=0.669 \mathrm{~mm}^{-1}$, 1997 measured reflections, 1863 unique $\left(\mathrm{R}_{\mathrm{int}}=0.0312\right)$ of which 1421 were considered as observed with $\mathrm{I} \geq 2 \sigma(\mathrm{I})$. Final indices: $\mathrm{R}_{1}\left(\mathrm{~F}_{\mathrm{o}}\right)=0.0726, \mathrm{w}_{2}\left(\mathrm{~F}^{2}\right)=0.3056$ for 252 refined parameters. The $\mathrm{O} 26$ and $\mathrm{O} 27$ atoms are disordered over two sites with occupancies of 0.82 and 0.18 . The structures were solved with direct methods using SHELXS97 and were refined anisotropically with full-matrix least-squares on $\mathrm{F}^{2}$ using SHELXL97. ${ }^{18,19}$ The hydrogen atoms were placed at calculated positions except those involved in $\mathrm{H}$-bonds and in weak interactions, found on difference maps and refined with riding constraints. The crystallographic data were deposited at the Cambridge Crystallographic Data Center under the numbers CCDC 292281 and 606880 for $\mathbf{2 a}$ and $\mathbf{2 c}$, respectively. Copies of the data can be obtained free of charge, on application to CCDC, 12 Union Road, Cambridge, CB21EZ, UK (fax +44 1223 336033) or e-mail: deposit@ccdc.camac.uk. 


\section{Acknowledgments}

The authors gratefully acknowledge the financial support of the Conselho Nacional de Desenvolvimento Científico e Tecnológico-CNPq (Edital Universal-2002, Processo 474592/03-0) and Fundação de Amparo à Pesquisa do Estado da Bahia-FAPESB (Edital Fluxo Contínuo-2004, Processo 1431040046342 and Edital PRODOC-2004 Processo 1431040048671). We also thank FAPESB for a fellowship to G.A.N.C., and CNPq for fellowships to I.V., F.C.M.Jr, L.C.S.N. and D.C.N. (PIBIC-UFBA), and for a research fellowship to S.C.

\section{Supplementary Information}

Available free of charge at http://jbcs.org.br, as PDF file.

\section{References}

1. Greenhill, J. V.; Lee, L. In Progress in Medicinal Chemistry; Ellis, G. P.; Luscombe, D. K., eds., Elsevier: New York, 1993, vol. 30, 203; Review on synthesis: Berlinck, R. G. S.; Kossuga, M. H.; Nascimento, A. M. In Science of Synthesis; J. Knight, ed., Georg Thieme Verlag: Stuttgart, 2005, vol. 18, 1117; Katritzky, A. R.; Rogovoy, B. V.; Arkivoc 2005, 4, 49.

2. For representative papers, see: Katritzky, A.; Rogovoy, B. V.; Cai, X.; Kirichenko, N.; Kovalenko, K. V.; J. Org. Chem. 2004, 69, 309; Gers, T.; Kunce, D.; Markowski, P.; Izdebski, J.; Synthesis 2004, 37; Miller, C. A.; Batey, R. A.; Org. Lett. 2004, 6, 699; Bowser, A. M.; Madalengoitia, J. S.; Org. Lett. 2004, 6, 3409; Porcheddu, A.; Giacomelli, G.; Chighine, A.; Masala, S.; Org. Lett. 2004, 6, 4925; Li, J.; Zhang, G.; Zhang, Z.; Fan, E.; J. Org. Chem. 2003, 68, 1611; Ong, T.-G.; Yap, G. P. A.; Richeson, D. S.; J. Am. Chem. Soc. 2003, 125, 8100; Zapf, C. W.; Goodman, M.; J. Org. Chem. 2003, 68, 10092; Ma, D.; Xia, C.; Jiang, J.; Zhang, J.; Tang, W.; J. Org. Chem. 2003, 68, 442; Ostresh, J. M.; Schoner, C. C.; Hamashin, V. T.; Nefzi, A.; Meyer, J-P.; Houghten, R. A.; J. Org. Chem. 1998, 63, 8622; Kearney, P. C.; Fernandez, M.; Flygare, J. A.; Tetrahedron Lett. 1998, 39, 2663; Dodd, D. S.; Wallace, O. B.; Tetrahedron Lett. 1998, 39, 5701; Josey, J. A.; Tareton, C. A.; Payne, C. E.; Tetrahedron Lett. 1998, 39, 5899; Schneider, S. E.; Bishop, P. A.; Salazar, M. A.; Bishop, O. A.; Anslyn, E. V.; Tetrahedron 1998, 54, 15063.

3. Feichtinger, K.; Sings, H. L.; Baker, T. J.; Matthews, K.; Goodman, M.; J. Org. Chem. 1998, 63, 8432; Feichtinger, K; Zapf, C.; Sings, H. L.; Goodman, M.; J. Org. Chem. 1998, 63, 3804; Barvian, M. R.; Showalter, H. D. H.; Doherty, A. M.; Tetrahedron Lett. 1997, 38, 6799; Yong, Y. F.; Kowalski, J. A.; Lipton, M. A.; J. Org. Chem. 1997, 62, 1540; Bernatowicz, M. S.; Y. Wu, Matsueda, G. R.; J. Org. Chem. 1992, 57, 2497.
4. Miel, H.; Rault, S.; Tetrahedron Lett. 1998, 39, 1565; Jeong, J-H.; Murray, B. W.; Takayama, S.; Wong, C.-H.; J. Am. Chem. Soc. 1996, 118, 4227. See also ref. 13.

5. Andreani, A.; Rambaldi, M.; Locatelli, A.; Bossa, R.; Fraccari, A.; Galatulas, I.; J. Med. Chem. 1992, 35, 4634.

6. Andreani, A.; Rambaldi, M.; Leoni, A.; Locatelli, A.; Bossa, R.; Fraccari, A.; Galatulas, I.; Salvatore, G.; J. Med. Chem. 1996, 39, 2852; Andreani, A.; Leoni, A.; Locatelli, A.; Morigi, R.; Rambaldi, M.; Recanatinia, M.; Garaliene, V.; Bioorg. Med. Chem. 2000, 8, 2359.

7. Gadad, A. K.; Mahajanshetti, C. S.; Nimbalkar, S.; Raichurkar, A.; Eur. J. Med. Chem. 2000, 35, 853.

8. Martins, T. L. C.; França, T. C. C.; Ramalho, T. C.; FigueroaVillar, J. D.; Synth. Commun. 2004, 34, 1; Messeder, J. C.; Tinoco, L. W.; Figueroa-Villar, J. D.; Souza, E. M.; Santa-Rita, R.; de Castro, S. L.; Bioorg. Med. Chem. Lett. 1995, 5, 3079; Borges, M. N.; Figueroa-Villar, J. D.; Biopolymers 2001, 62, 9; Chang, K. P.; Steiger, R. F; Dave, C.; Cheng, W. C.; J. Protozool. 1978, 25, 145; Ulrich, P.C.; Grady, R.W.; Cerami, A.; Drug Dev. Res. 1982, 2, 219; Ulrich, P. C.; Cerami, A.; J. Med. Chem. 1984, 27, 35.

9. Cunha, S.; Costa, M. B.; Napolitano, H. B.; Lauriucci, C.; Vecanto, I.; Tetrahedron 2001, 57, 1671; Cunha, S.; Lima, B. R.; Souza, A. R.; Tetrahedron Lett. 2002, 43, 49; Cunha, S.; Rodrigues Jr., M. T.; Silva, C. C.; Napolitano, H. B.; Vencato, I.; Lariucci, C.; Tetrahedron 2005, 61, 10536; Cunha, S.; Rodrigues Jr., M. T.; Tetrahedron Lett. 2006, 47, 49.

10. Indukumari, P. V.; Joshua, C. P.; Rajan, V. P.; Indian J. Chem. 1981, 20B, 384.

11. We tentatively initiated the preparation of the substituted thiosemicarbazones by reacting thiosemicarbazone thioesters with amines, as described in: Greenbaum, D. C.; Mackey, Z.; Hansell, E.; Doyle, P.; Gut, J.; Caffrey, C. R.; Lehrman, J.; Rosenthal, P. J.; McKerrow, J. H.; Chibale, K.; J. Med. Chem. 2004, 47, 3212. However, we abandoned this route for two reasons. First: in our hands, methyl hydrazinecarbodithioate, the precursor of the thiosemicarbazone thioesters, was obtained in very low yield, even though the above authors reported a yield great than $90 \%$. For alternative preparations of methyl hydrazinecarbodithioate with reported yields of 50\% and 60\% respectively, see: Klayman, D. L.; Bartosevich, J. F.; Griffin, T. S.; Mason, C. J.; Scovil, J. P.; J. Med. Chem. 1979, 22, 855; Hu, W. X.; Zhou, W.; Xia, C. N.; Wei, X.; Bioorg. Med. Chem. Lett. 2006, 16, 2213. Second, for safety reasons: methyl hydrazinecarbodithioate is a nasty smelling compound, and its odor has a strong effect of dilution. People exposed to this compound in our lab suffered from headaches and respiratory tract irritations, even working in a well ventilated hood.

12. Farrugia, L. J.; J. Appl. Cryst. 1997, 30, 565.

13. For precedent of carbodiimide as intermediate in the mechanism proposed for guanidine synthesis from thioureas, see: Poss, M. 
A.; Iwanowicz, E.; Reid, J. A.; Lin, J.; Gu, Z.; Tetrahedron Lett. 1992, 33, 5933; Kim, K. S.; Qian, L.; Tetrahedron Lett. 1993, 48, 7677; Levallet, C.; Lerpiniere, J.; Ko, S. Y.; Tetrahedron 1997, 53, 5291. For precedent of the addition-elimination mechanism proposal in guanidine formation from thioureas, see: Wermann, K.; Walther, M.; Günther, W.; Görls, H.; Anders, E.; Tetrahedron 2005, 61, 673; Wermann, K.; Walther, M.; Günther, W.; Görls, H.; Anders, E.; J. Org. Chem. 2001, 66, 720.

14. He, Y.; Yang, J.; Wu, B.; Risen, L.; Swayze, E. E.; Bioorg. Med. Chem. Lett. 2004, 14, 1217; Cassell, G. H.; Mekalanos, J.; J. Am. Med. Assoc. 2001, 285, 601; Wright, G. D.; Chem. Biol. 2000, 7, R127; Heinemann, J. A.; Ankenbauer, R. G.; AmabileCuevas, C. F.; Drug Discov. Today 2000, 5, 195; Cunha, B. A.; Drugs Today 1998, 34, 691; Amyes, S. G. B.; Gemmell, C. G.; J. Med. Microbiol. 1997, 46, 436.

15. Rybak, M. J.; Akins, R. L.; Drugs 2001, 61, 1; Poole, K.; Curr. Opin. Microbiol. 2001, 4, 500; Marchese, A.; Schito, G. C.;
Debbia, E. A.; J. Chemother. 2000, 12, 459; Livermore, D. M.; Int. J. Antimicrob. Agents 2000, 16, S3; Cetinkaya, Y.; Falk, P.; Mayhall, C. G.; Clin. Microbiol. Rev. 2000, 13, 686.

16. Kusucu, C.; Rapino, B.; McDermott, L.; Hadley, S.; J. Clin. Microbiol. 2004, 42, 1224.

17. National Committee for Clinical Laboratory Standards (NCCLS), 2002. Performance standards for antimicrobial susceptibility testing. Twelfth International Supplement. M100S12. P.A. Wayne.

18. G. M. Sheldrick; SHELXS97 and SHELXL97, University of Göttingen, Germany, 1997.

19. Enraf-Nonius 1993. CAD-4/PC software, version 1.2. EnrafNonius, Delft, The Netherlands.

Received: September 13, 2008 Web Release Date: March 27, 2009 


\section{Guanylation of Thiosemicarbazones: A New Synthetic Route to Polysubstituted Guanylhydrazones with Antimicrobial Activity}

Silvio Cunha, ${ }^{*}, a$ Fernando César de Macedo Jr., ${ }^{a}$ Giselle A. N. Costa, ${ }^{a}$ Daniela C. Neves, ${ }^{a}$ Lourdes Cardoso de Souza Neta, ${ }^{a}$ Ivo Vencato, ${ }^{b}$ José R. Sabino ${ }^{b}$ and Carlito Lariucci ${ }^{b}$

${ }^{a}$ Instituto de Química, Universidade Federal da Bahia, Campus de Ondina, 40170-290 Salvador - BA, Brazil ${ }^{b}$ Instituto de Física, Universidade Federal de Goiás, CP 131, 74001-970 Goiânia - GO, Brazil

The spectra were acquired with a Varian Gemini-300 spectrometer operating at $300.069 \mathrm{MHz}$ for ${ }^{1} \mathrm{H}$ and $75.458 \mathrm{MHz}$ for ${ }^{13} \mathrm{C}$ using a $5 \mathrm{~mm}$ direct probe unless otherwise indicated.

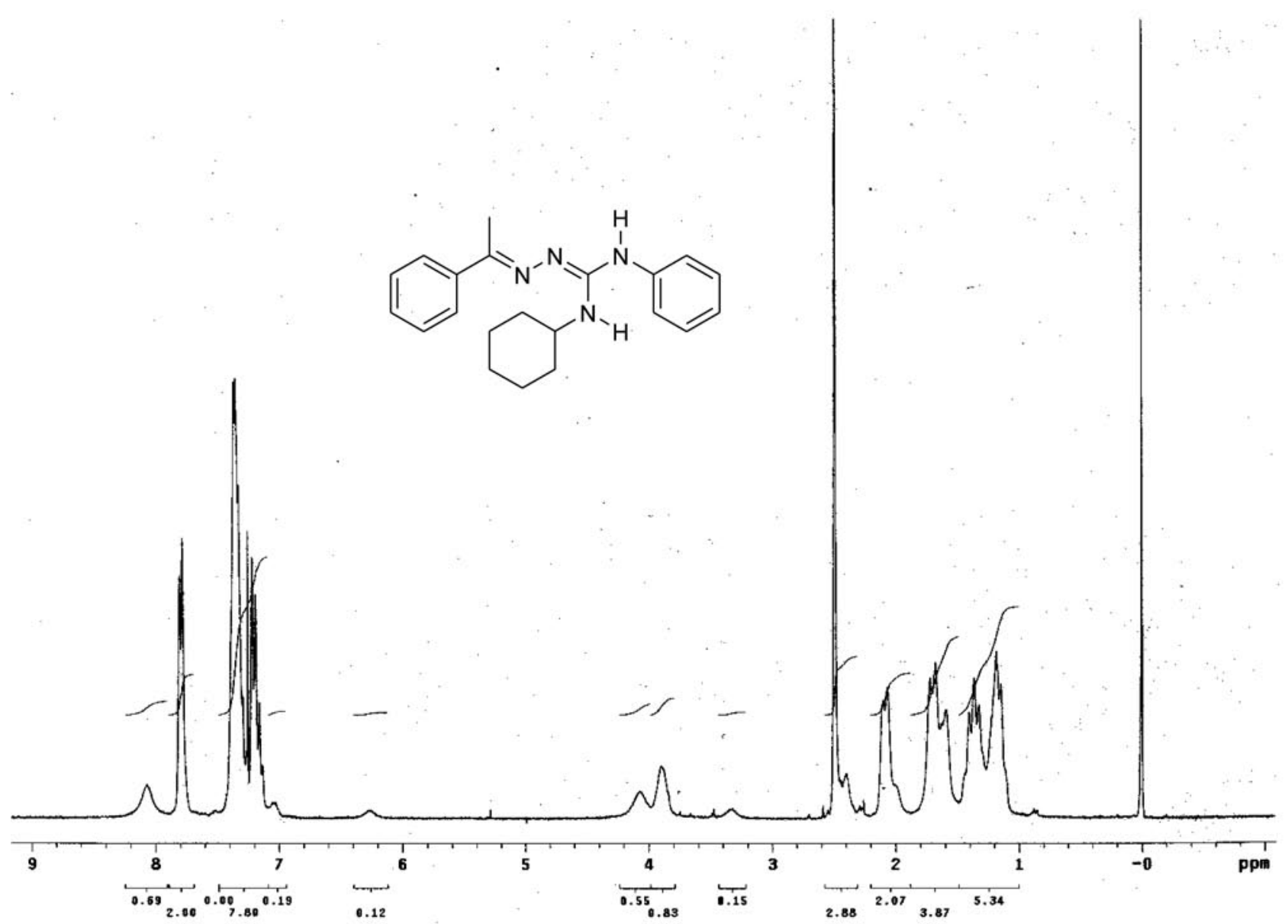

Figure S1. Full ${ }^{1} \mathrm{H}$ NMR spectrum of compound $2 \mathbf{a}\left(\mathrm{CDCl}_{3}\right)$.

*e-mail: silviodc@ufba.br 


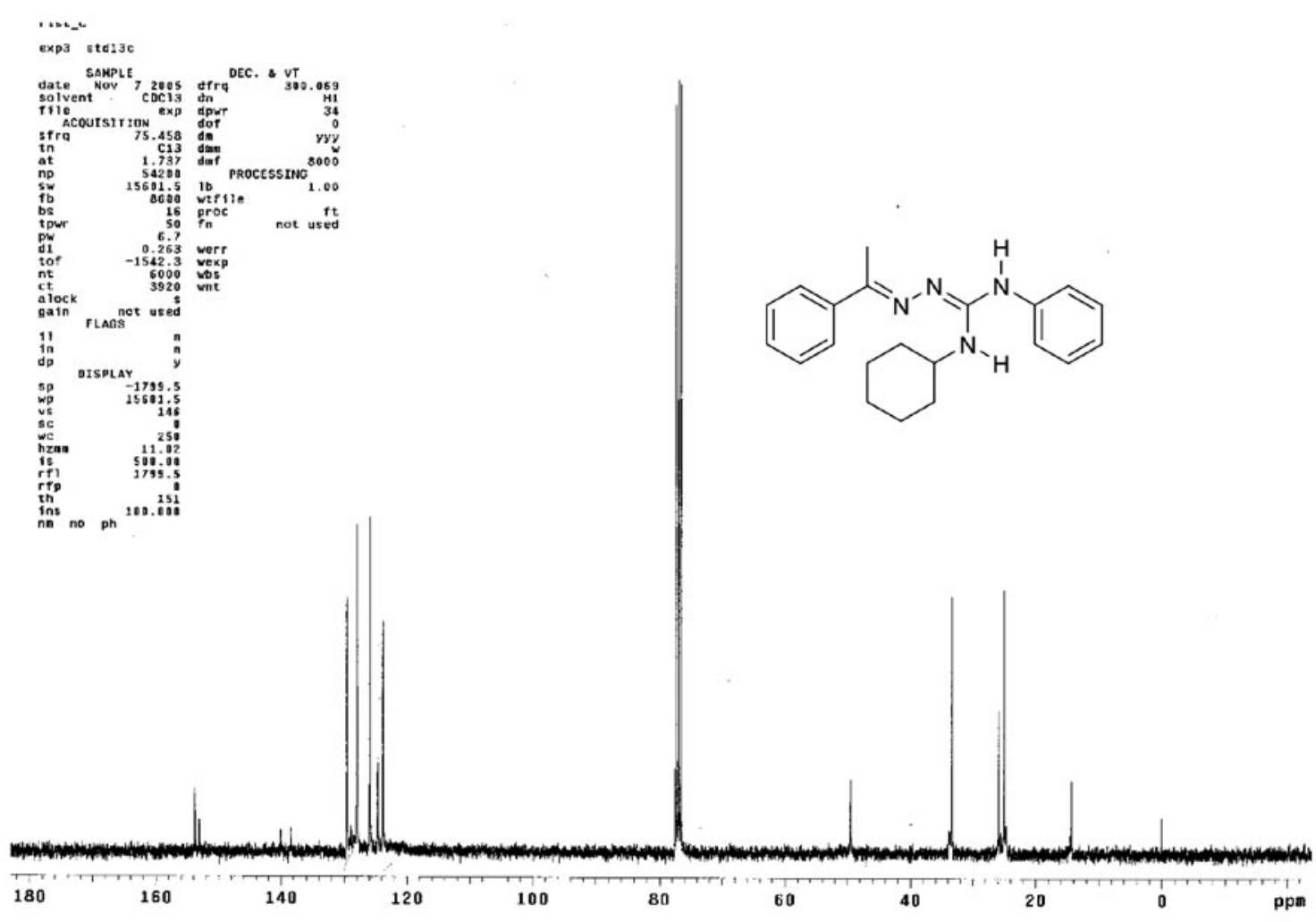

Figure S2. Full ${ }^{13} \mathrm{C}$ NMR spectrum of compound $\mathbf{2 a}\left(\mathrm{CDCl}_{3}\right)$.

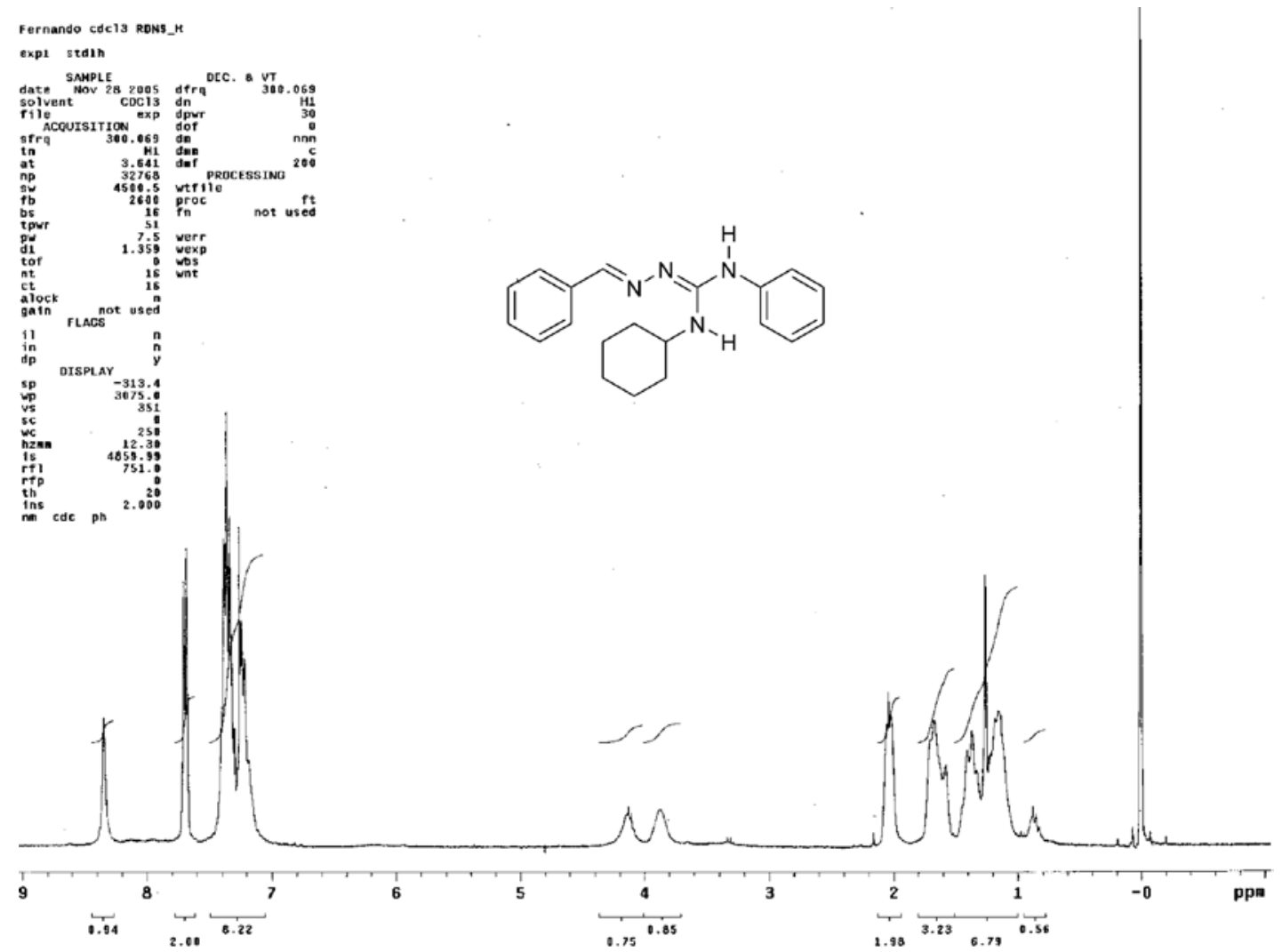

Figure S3. Full ${ }^{1} \mathrm{H}$ NMR spectrum of compound $\mathbf{2 b}\left(\mathrm{CDCl}_{3}\right)$. 


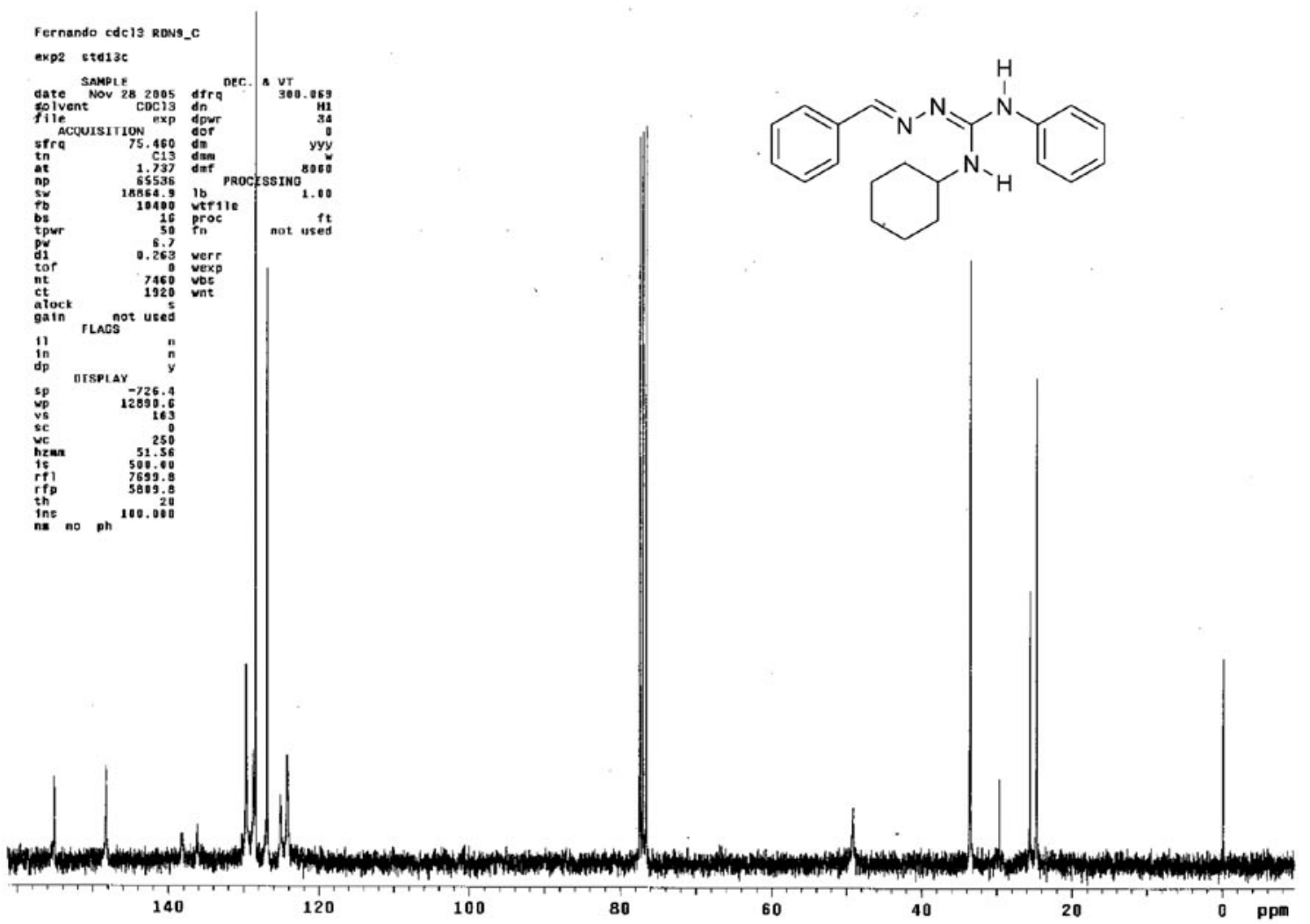

Figure S4. Full ${ }^{13} \mathrm{C}$ NMR spectrum of compound $2 \mathbf{b}\left(\mathrm{CDCl}_{3}\right)$.

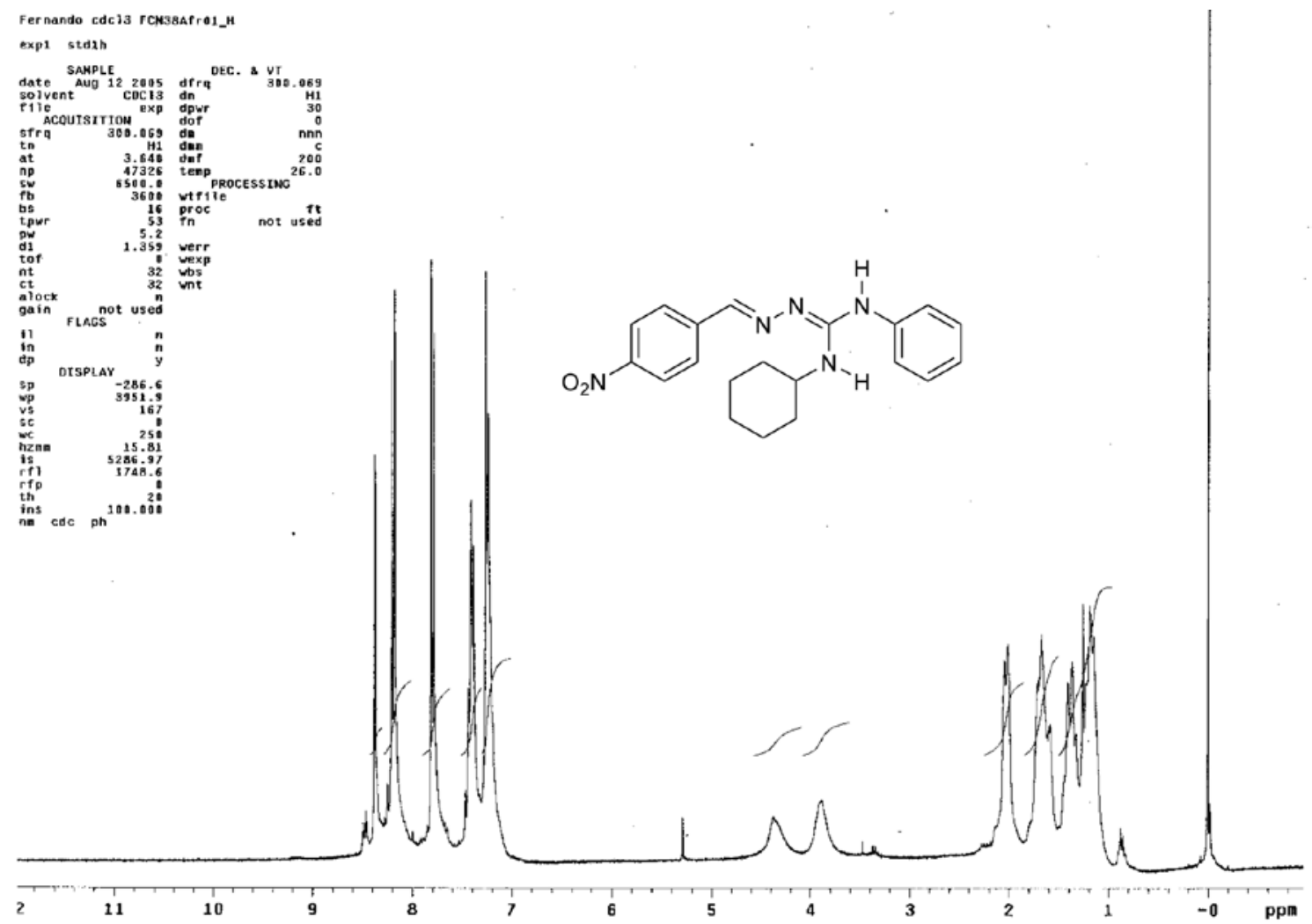

Figure S5. Full ${ }^{1} \mathrm{H}$ NMR spectrum of compound $2 \mathrm{c}\left(\mathrm{CDCl}_{3}\right)$. 


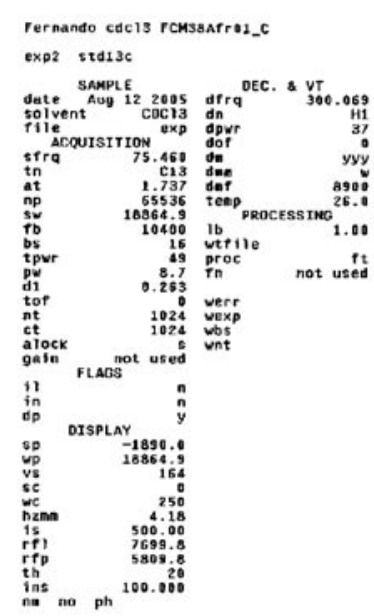

Figure S6. Full ${ }^{13} \mathrm{C}$ NMR spectrum of compound $2 \mathbf{c}\left(\mathrm{CDCl}_{3}\right)$.
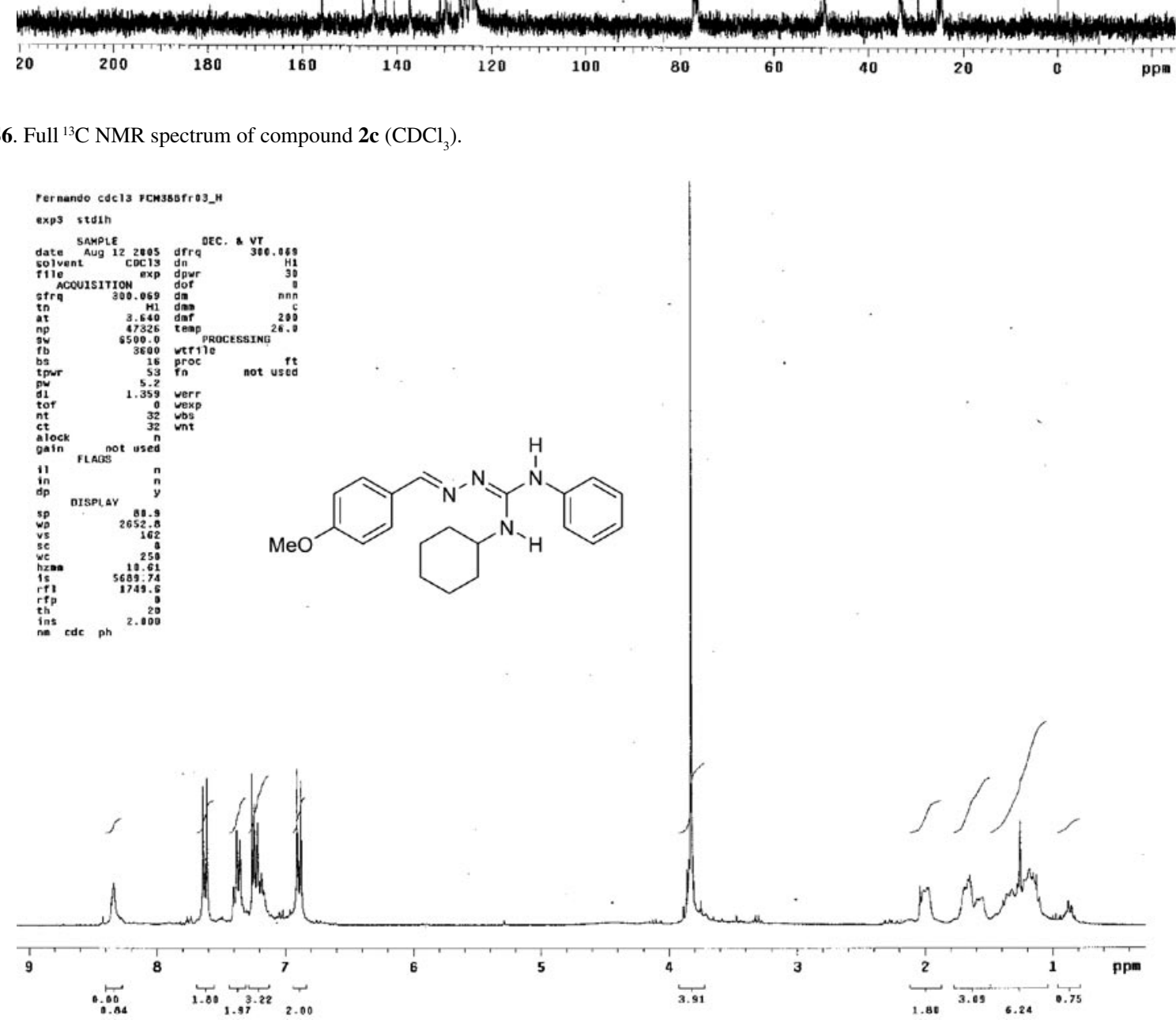

Figure S7. Full ${ }^{1} \mathrm{H}$ NMR spectrum of compound $2 \mathbf{d}\left(\mathrm{CDCl}_{3}\right)$. 

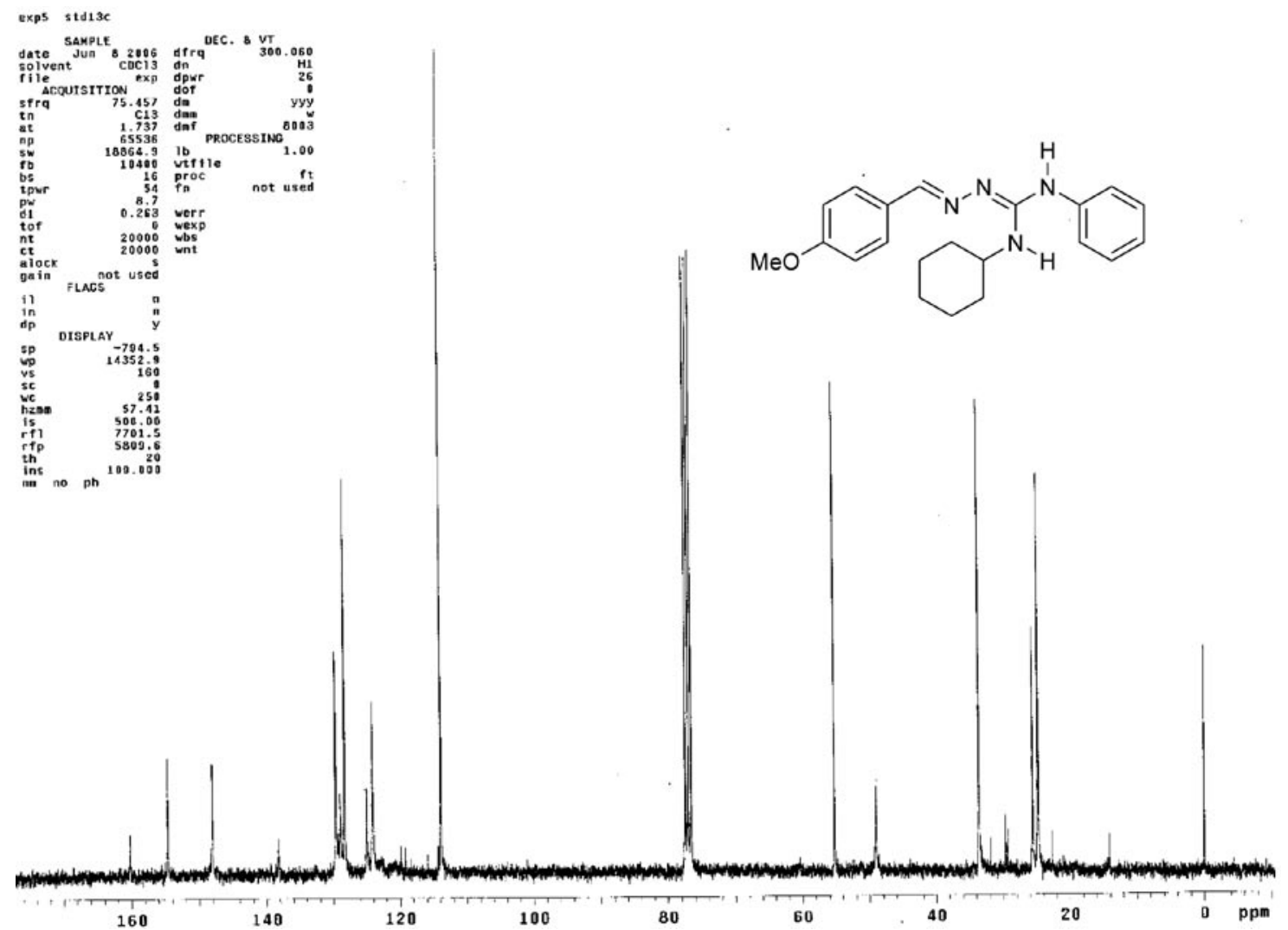

Figure S8. Full ${ }^{13} \mathrm{C}$ NMR spectrum of compound $2 d\left(\mathrm{CDCl}_{3}\right)$.

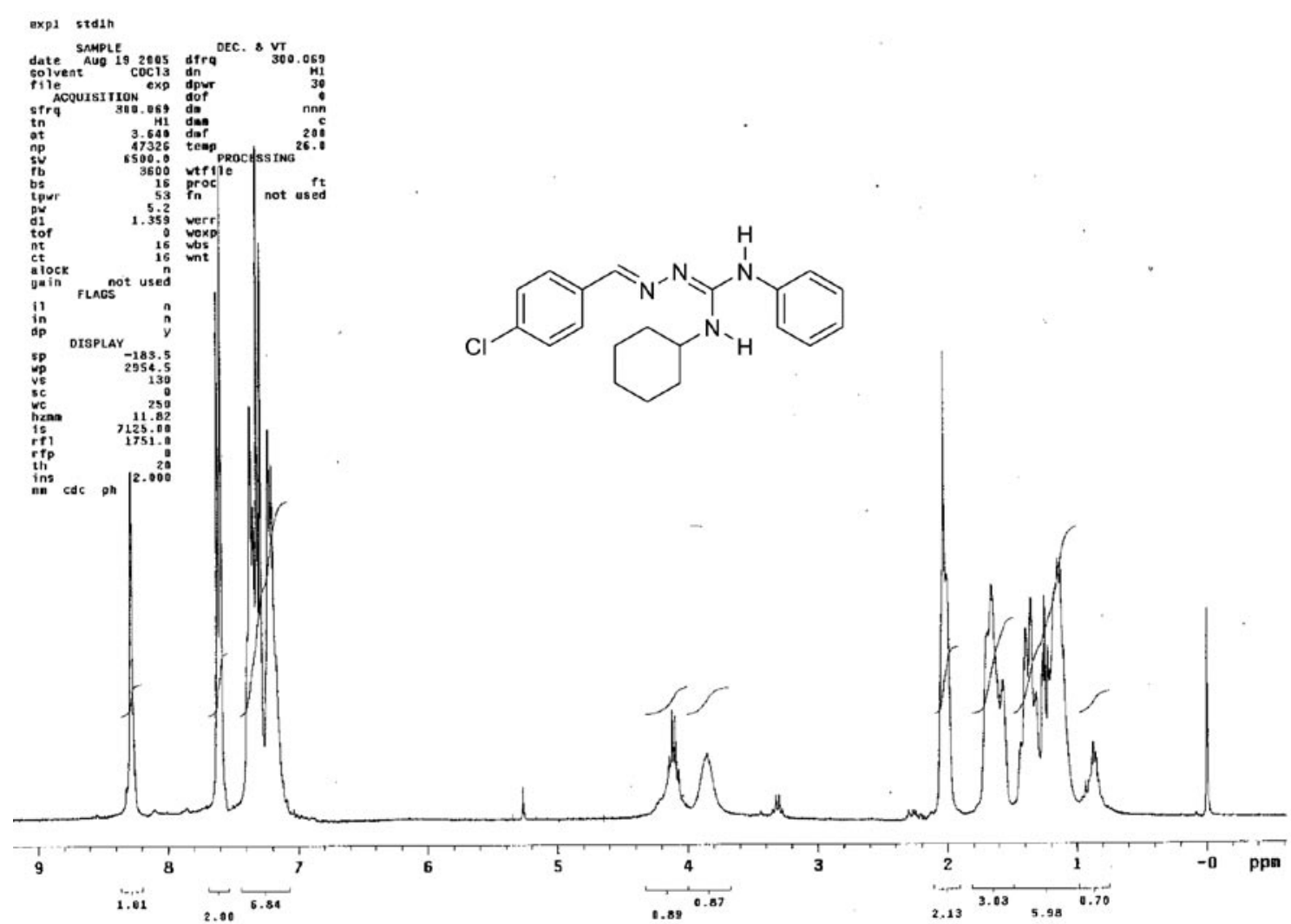

Figure S9. Full ${ }^{1} \mathrm{H}$ NMR spectrum of compound $2 \mathbf{e}\left(\mathrm{CDCl}_{3}\right)$. 


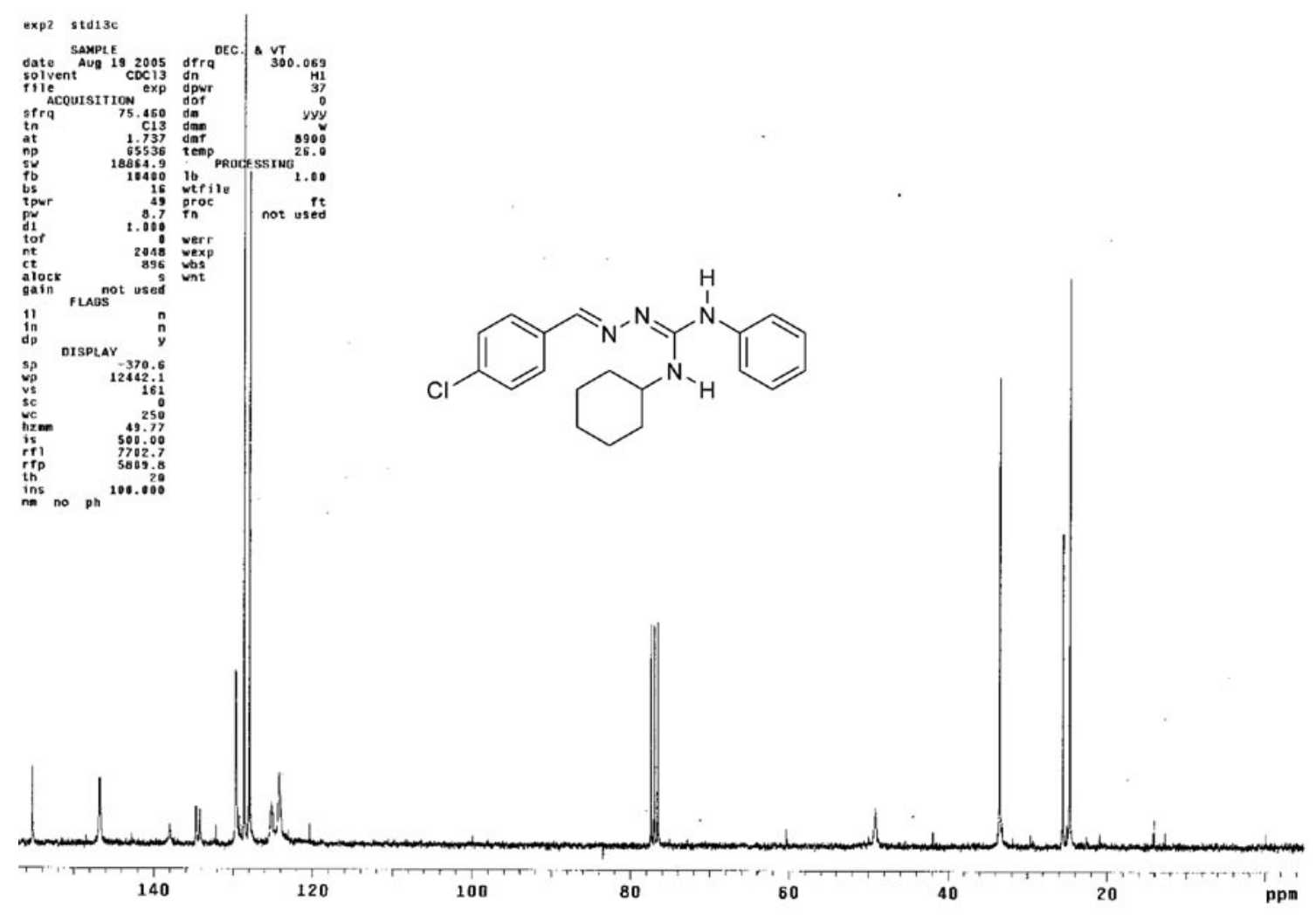

Figure S10. Full ${ }^{13} \mathrm{C}$ NMR spectrum of compound $2 \mathrm{e}\left(\mathrm{CDCl}_{3}\right)$.

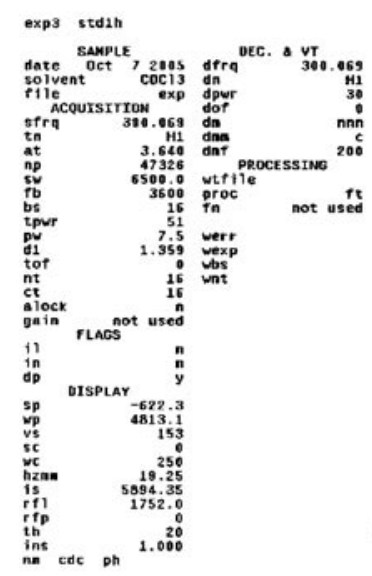<smiles>Oc1ccccc1/C=N/N=C(\Nc1ccccc1)NC1CCCCC1</smiles>

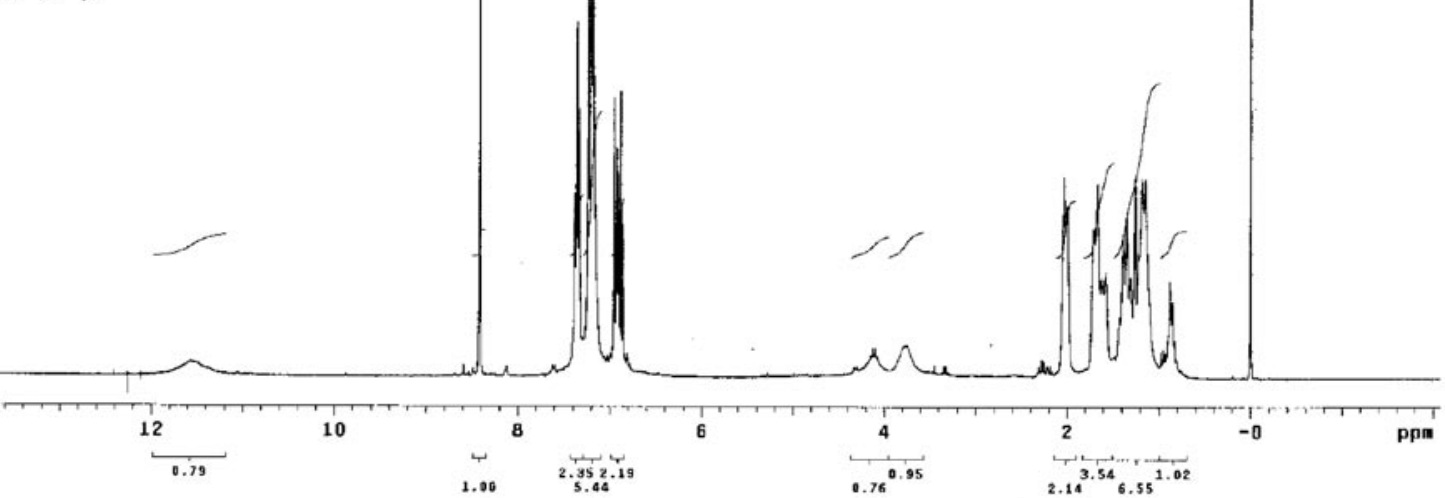

Figure S11. Full ${ }^{1} \mathrm{H}$ NMR spectrum of compound $\mathbf{2 f}\left(\mathrm{CDCl}_{3}\right)$. 


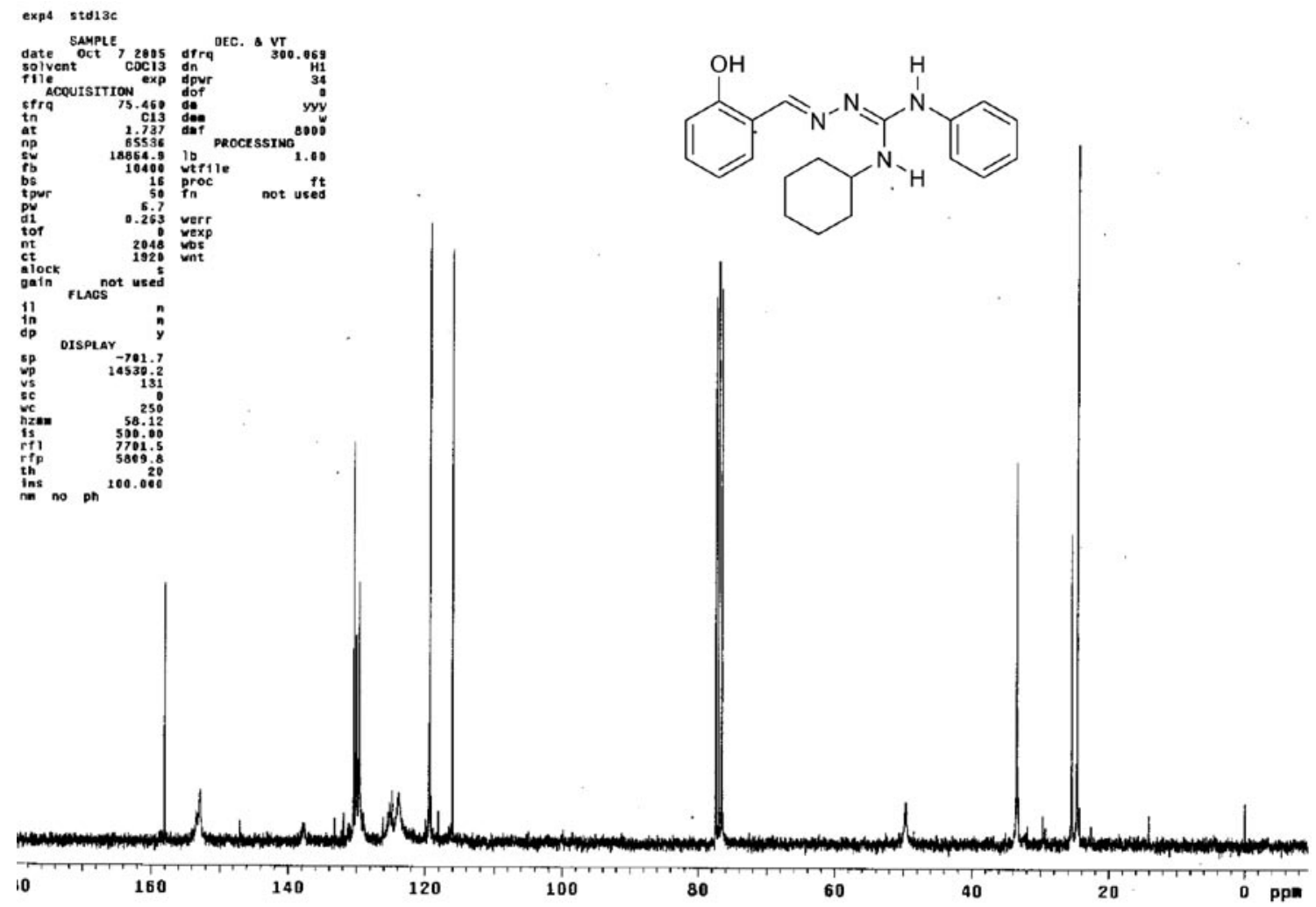

Figure S12. Full ${ }^{13} \mathrm{C}$ NMR spectrum of compound $2 \mathbf{f}\left(\mathrm{CDCl}_{3}\right)$.
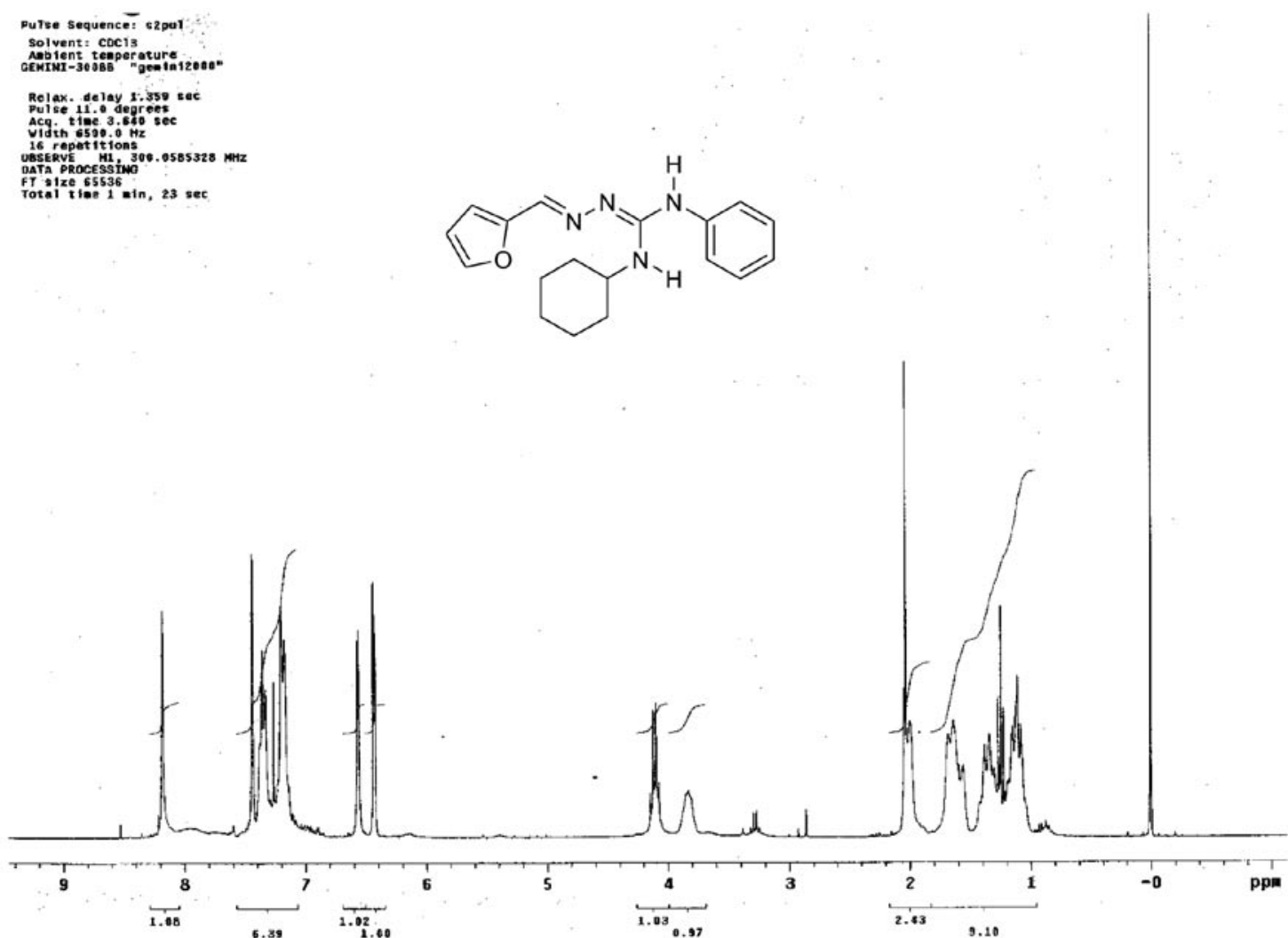

Figure S13. Full ${ }^{1} \mathrm{H}$ NMR spectrum of compound $2 \mathrm{~g}\left(\mathrm{CDCl}_{3}\right)$. 

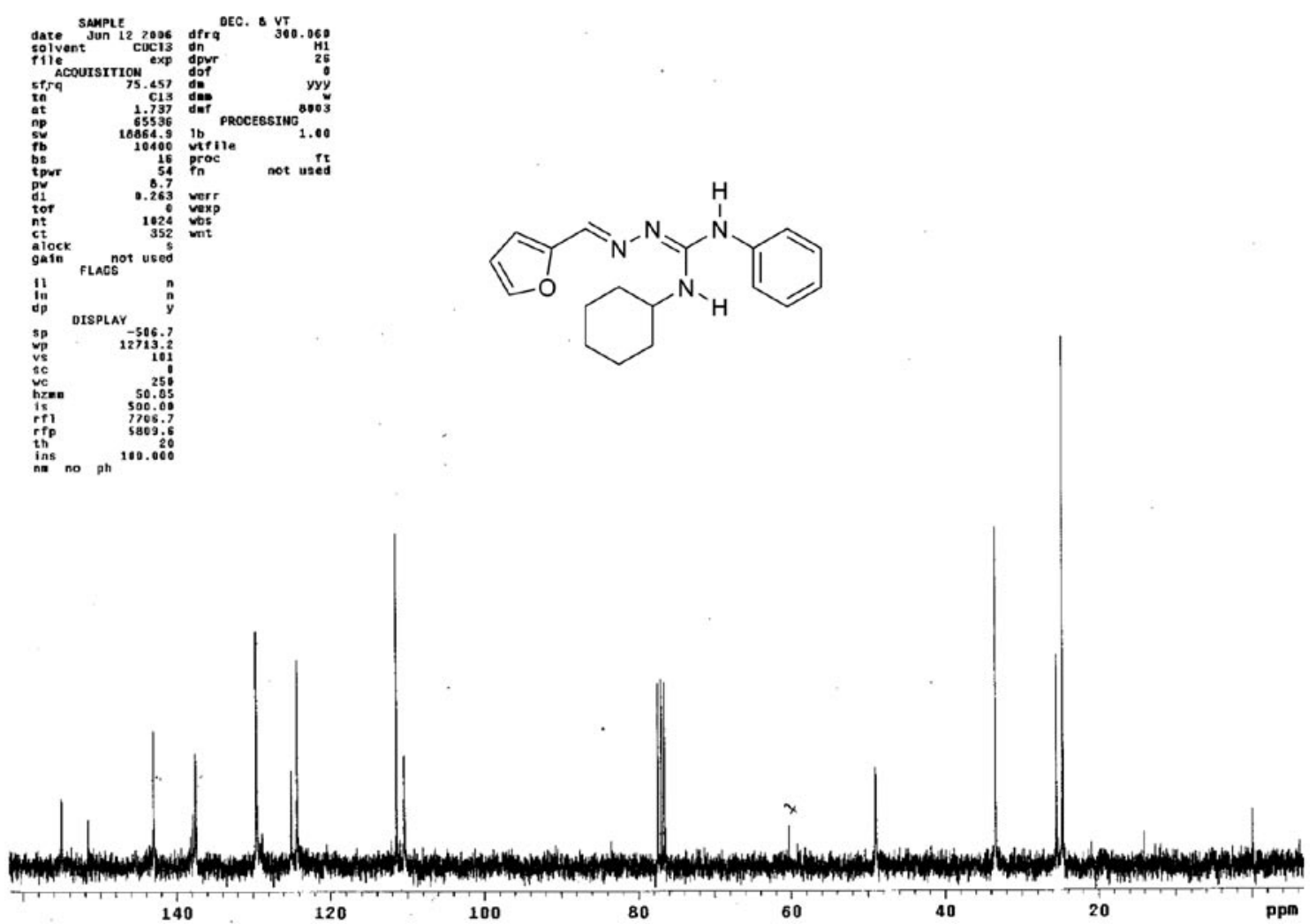

Figure S14. Full ${ }^{13} \mathrm{C}$ NMR spectrum of compound $2 \mathrm{~g}\left(\mathrm{CDCl}_{3}\right)$.
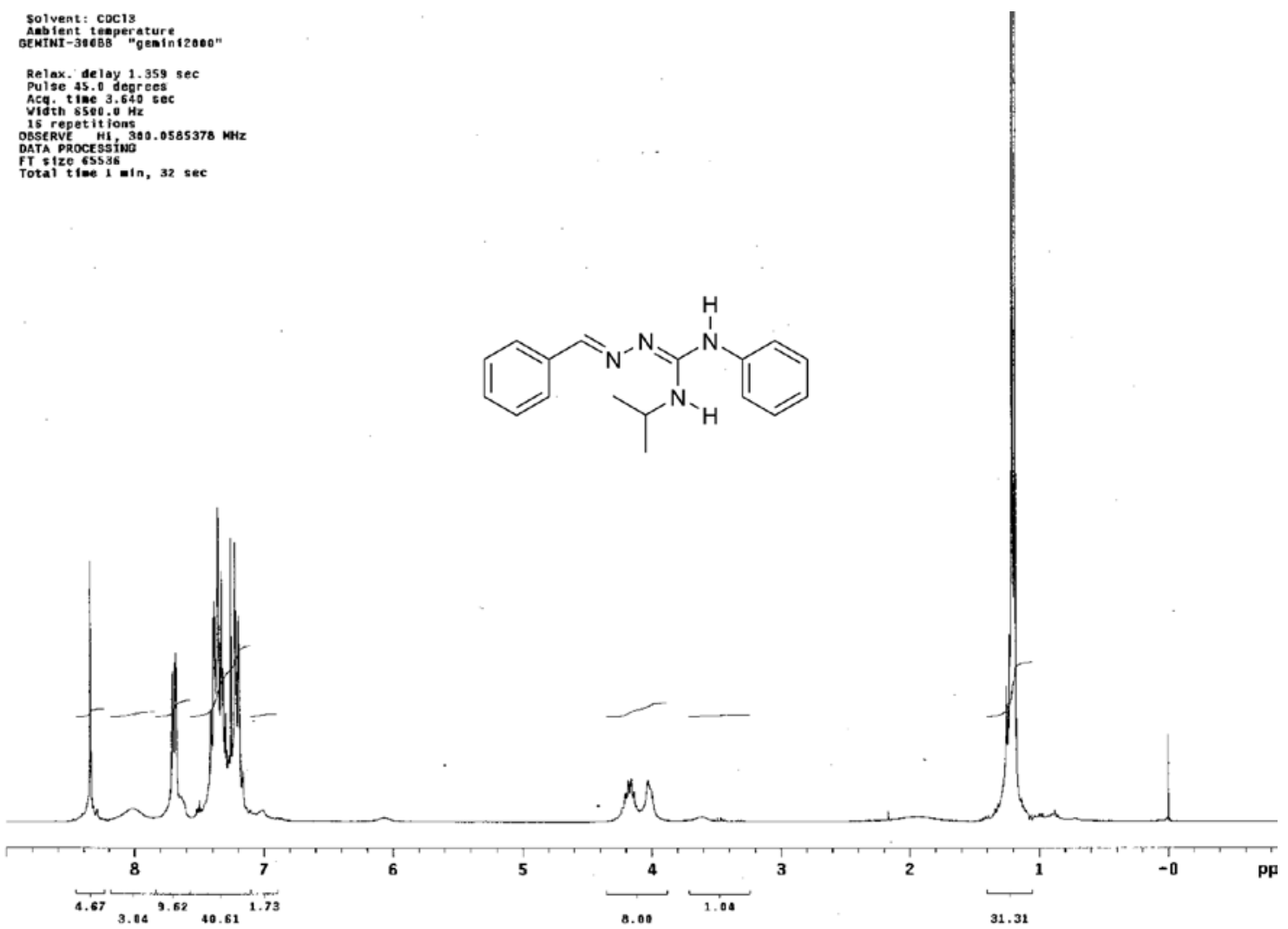

Figure S15. Full ${ }^{1} \mathrm{H}$ NMR spectrum of compound $2 \mathbf{h}\left(\mathrm{CDCl}_{3}\right)$. 

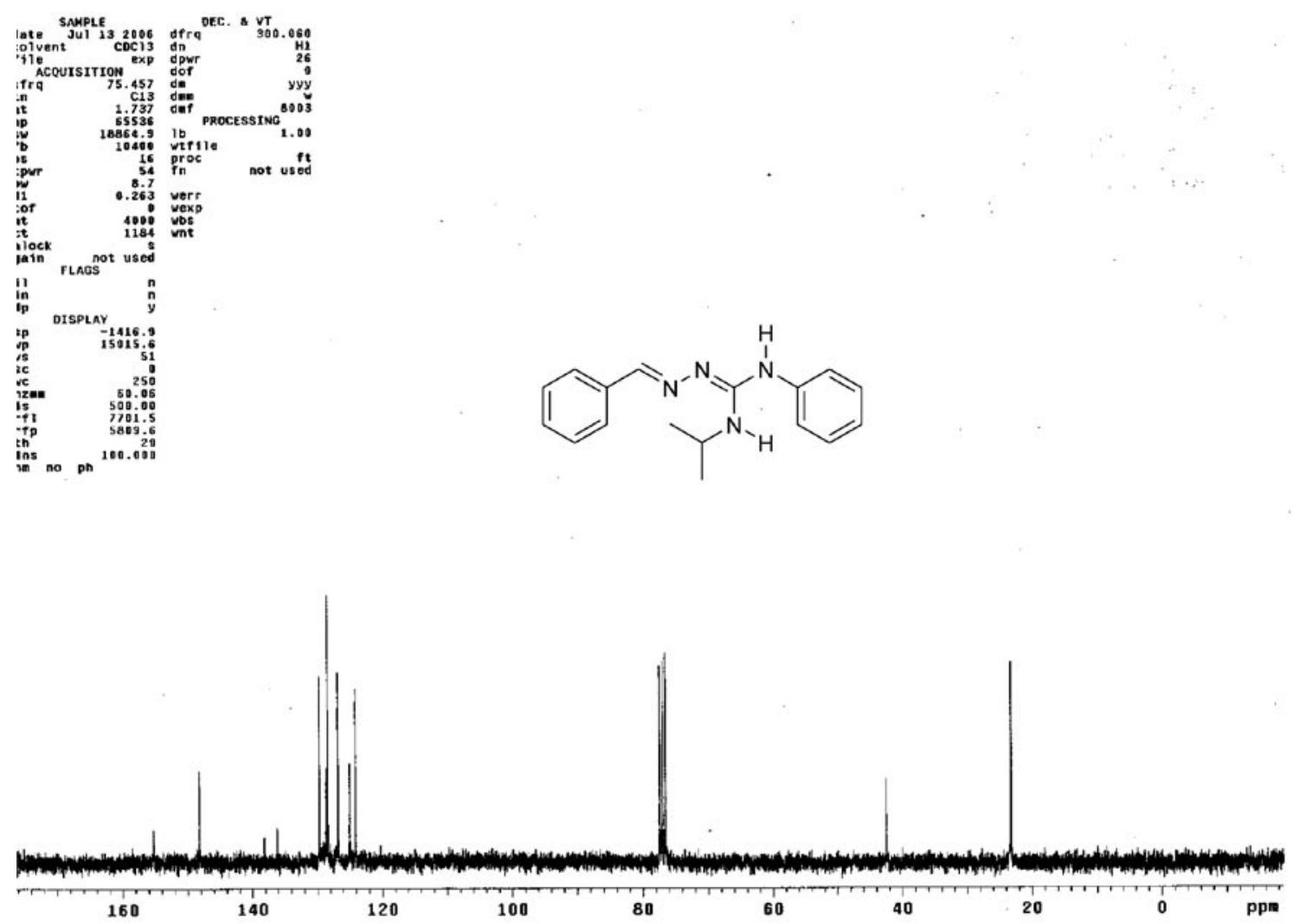

Figure S16. Full ${ }^{13} \mathrm{C}$ NMR spectrum of compound $\mathbf{2 h}\left(\mathrm{CDCl}_{3}\right)$.

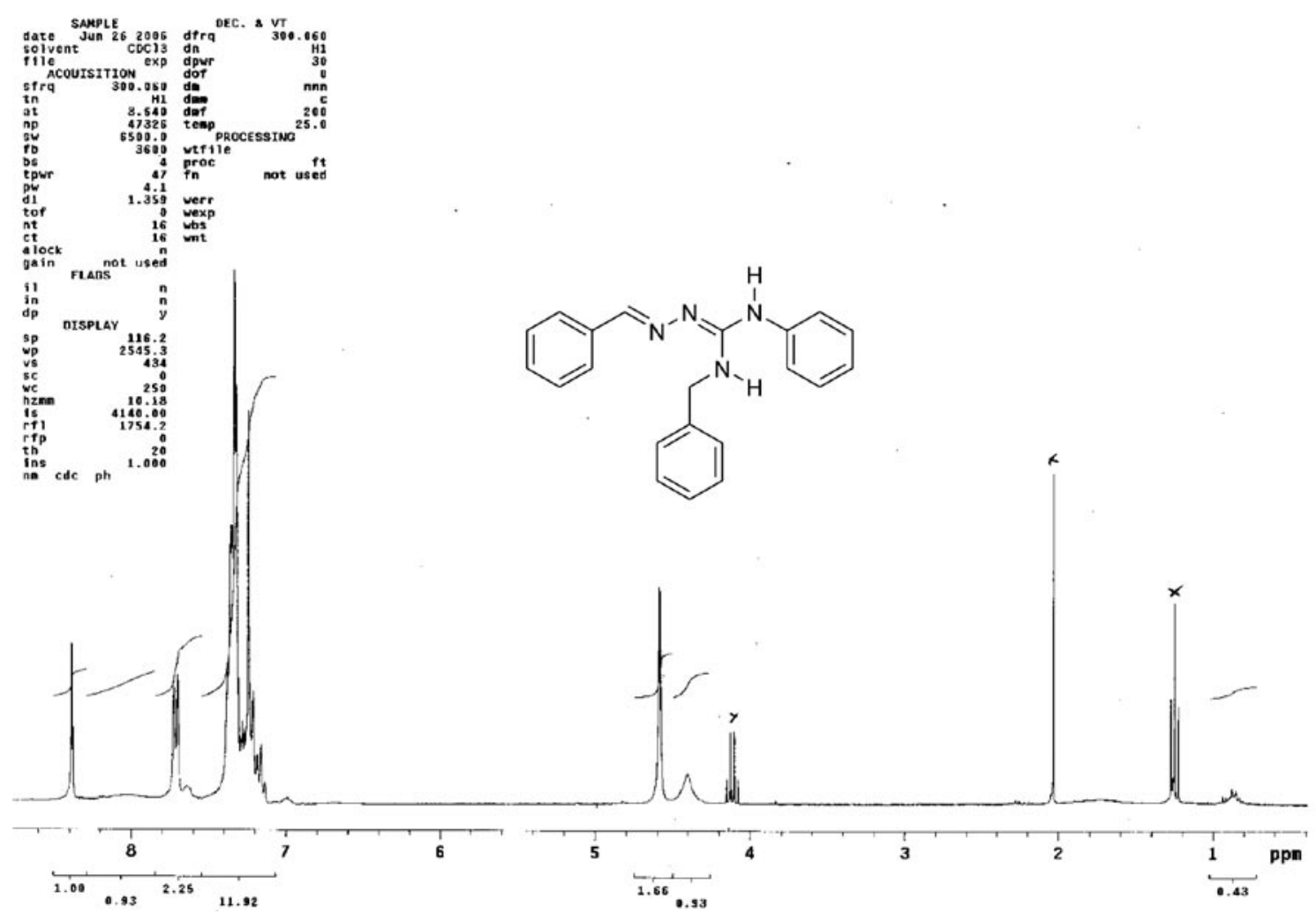

Figure S17. Full ${ }^{1} \mathrm{H}$ NMR spectrum of compound $2 \mathbf{i}\left(\mathrm{CDCl}_{3}\right)$. 


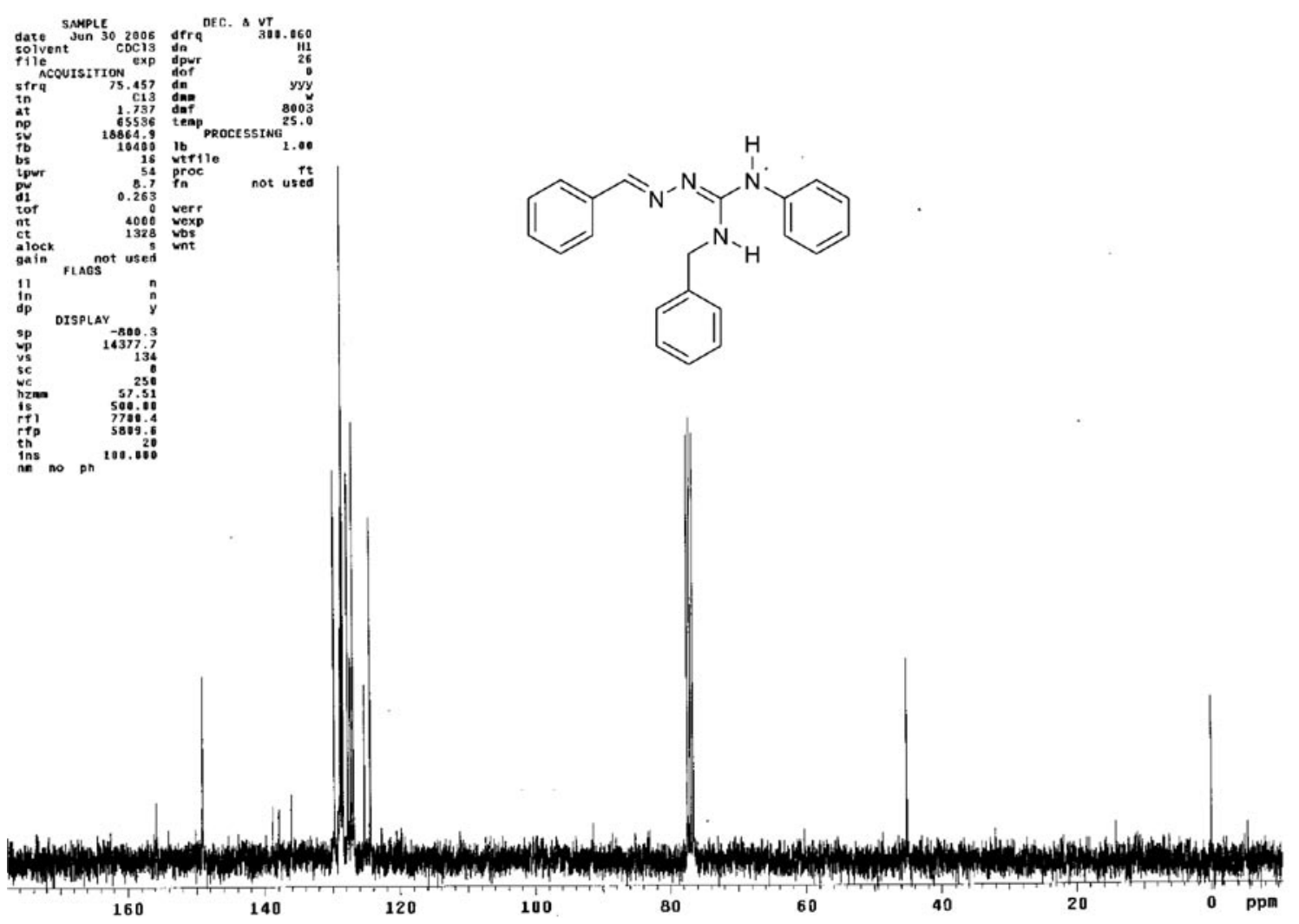

Figure S18. Full ${ }^{13} \mathrm{C}$ NMR spectrum of compound $\mathbf{2 i}\left(\mathrm{CDCl}_{3}\right)$.

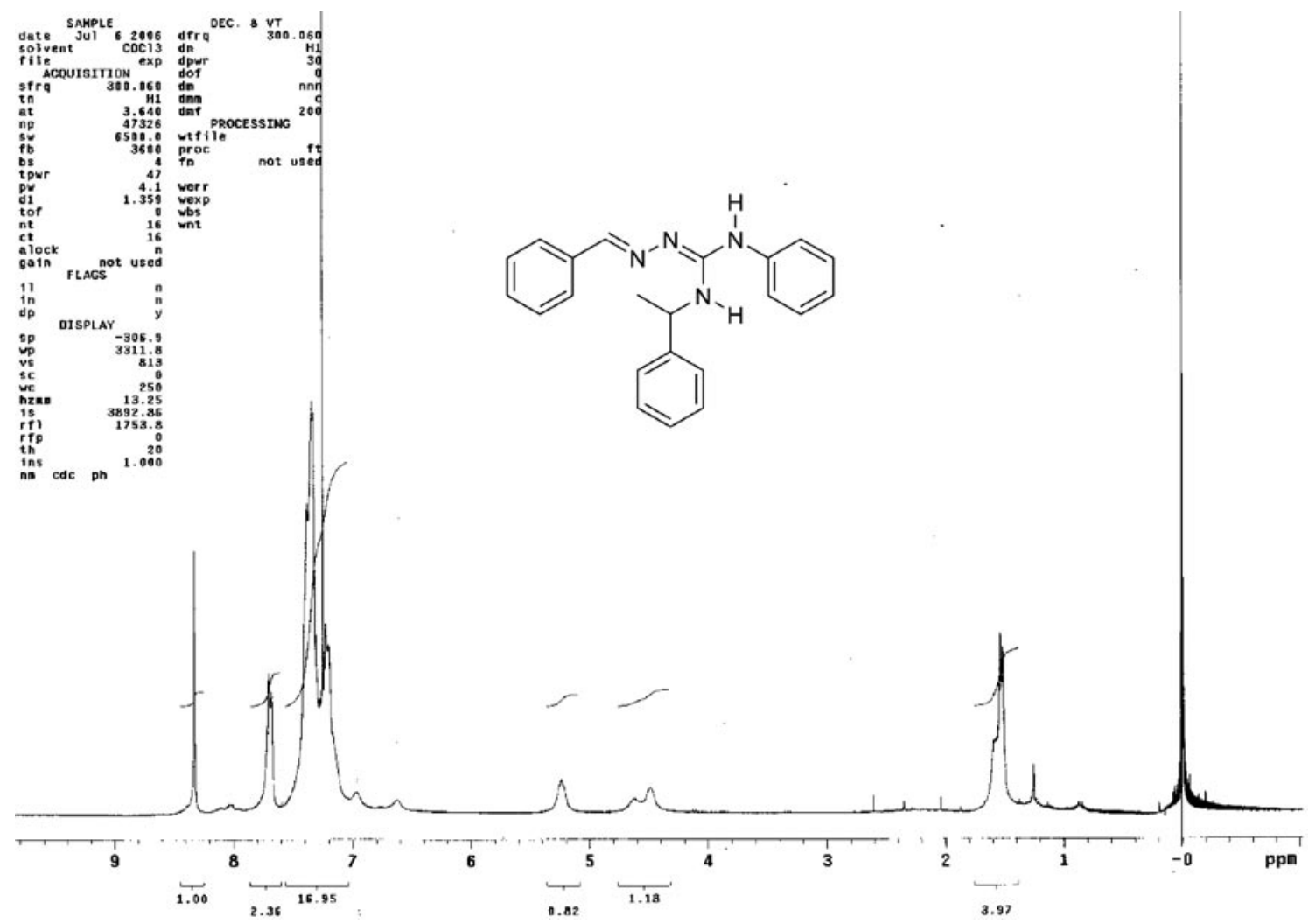

Figure S19. Full ${ }^{1} \mathrm{H}$ NMR spectrum of compound $\mathbf{2 j}\left(\mathrm{CDCl}_{3}\right)$. 

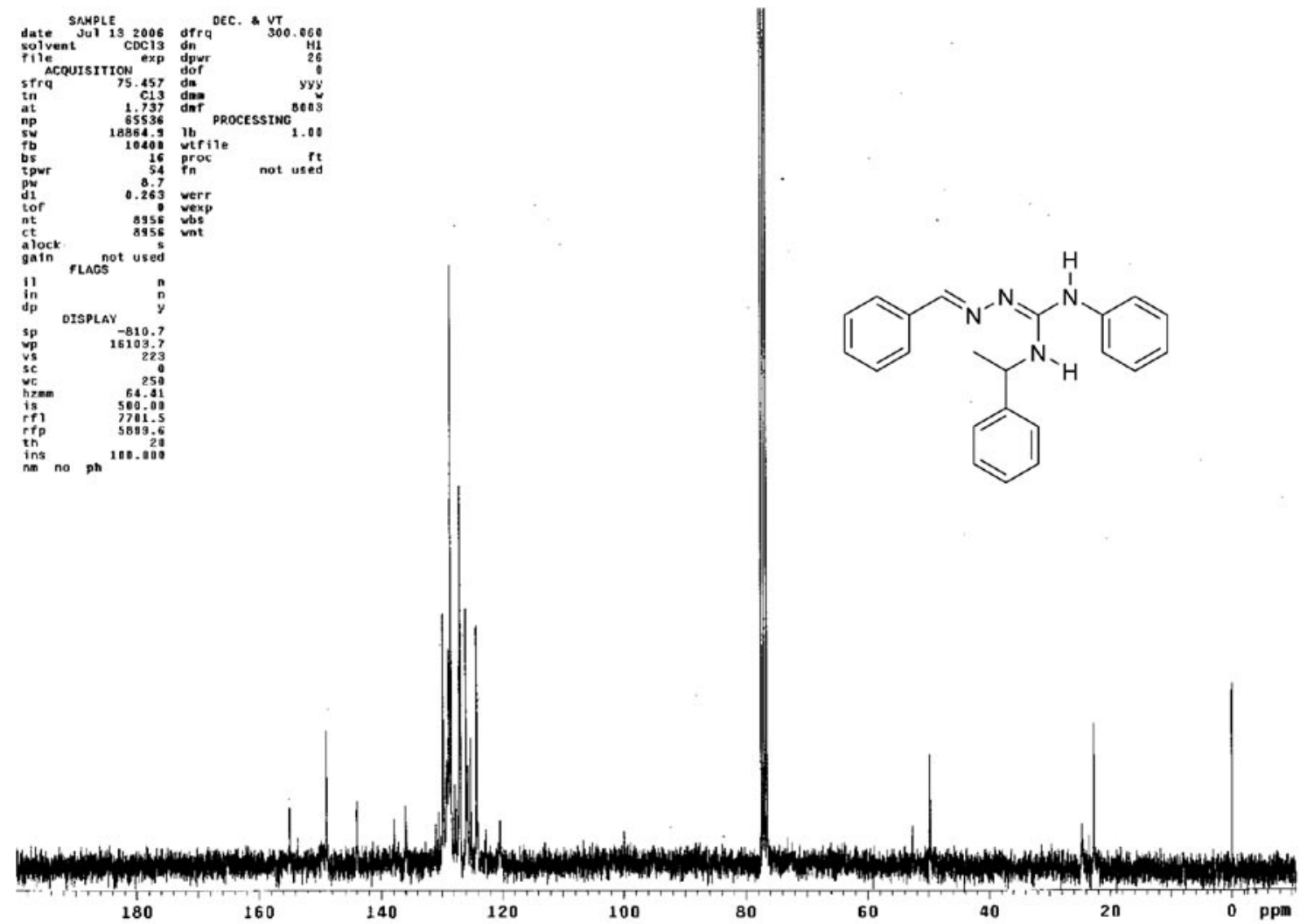

Figure S20. Full ${ }^{13} \mathrm{C}$ NMR spectrum of compound $2 \mathbf{j}\left(\mathrm{CDCl}_{3}\right)$.

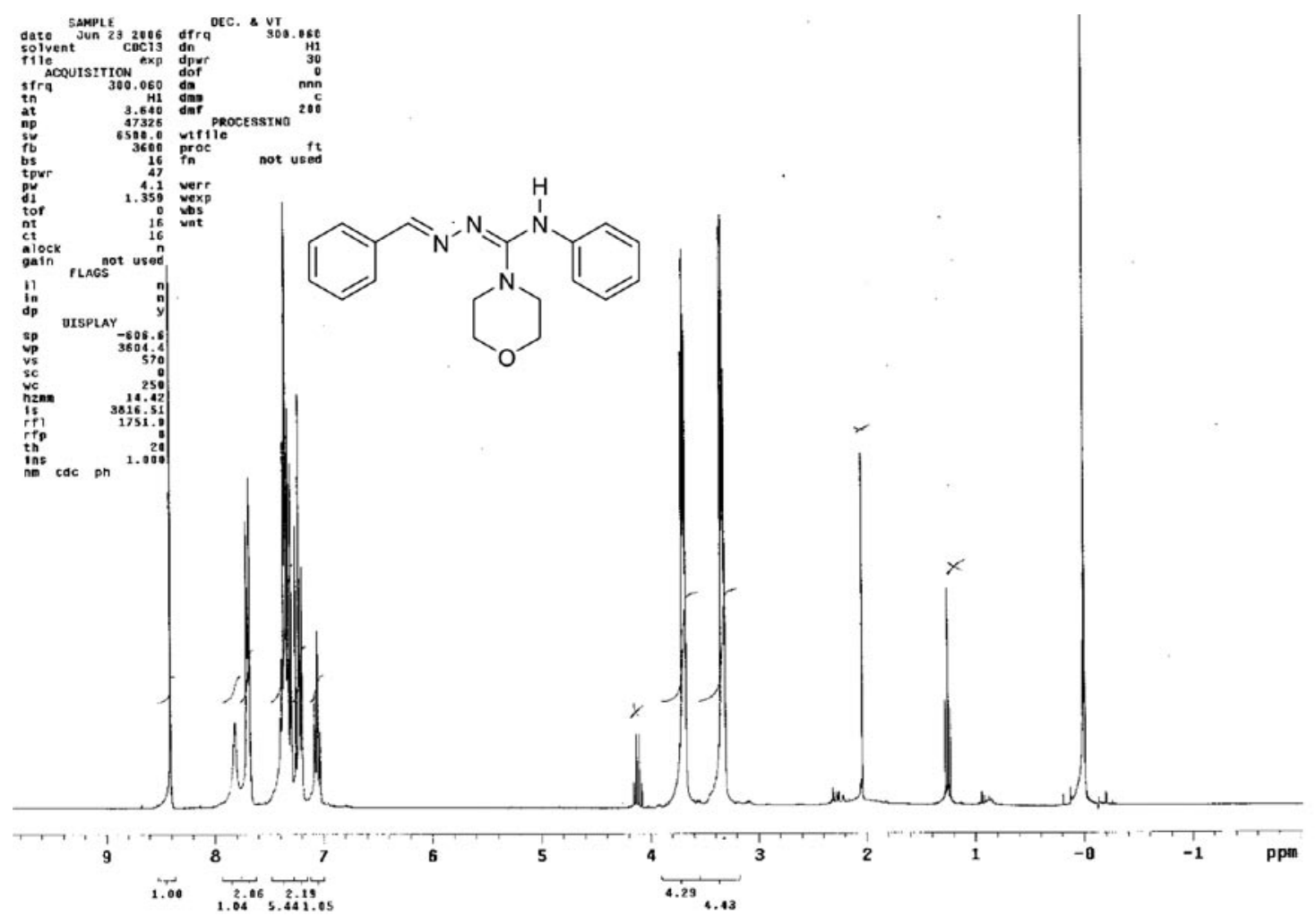

Figure S21. Full ${ }^{1} \mathrm{H}$ NMR spectrum of compound $\mathbf{2 k}\left(\mathrm{CDCl}_{3}\right)$. 


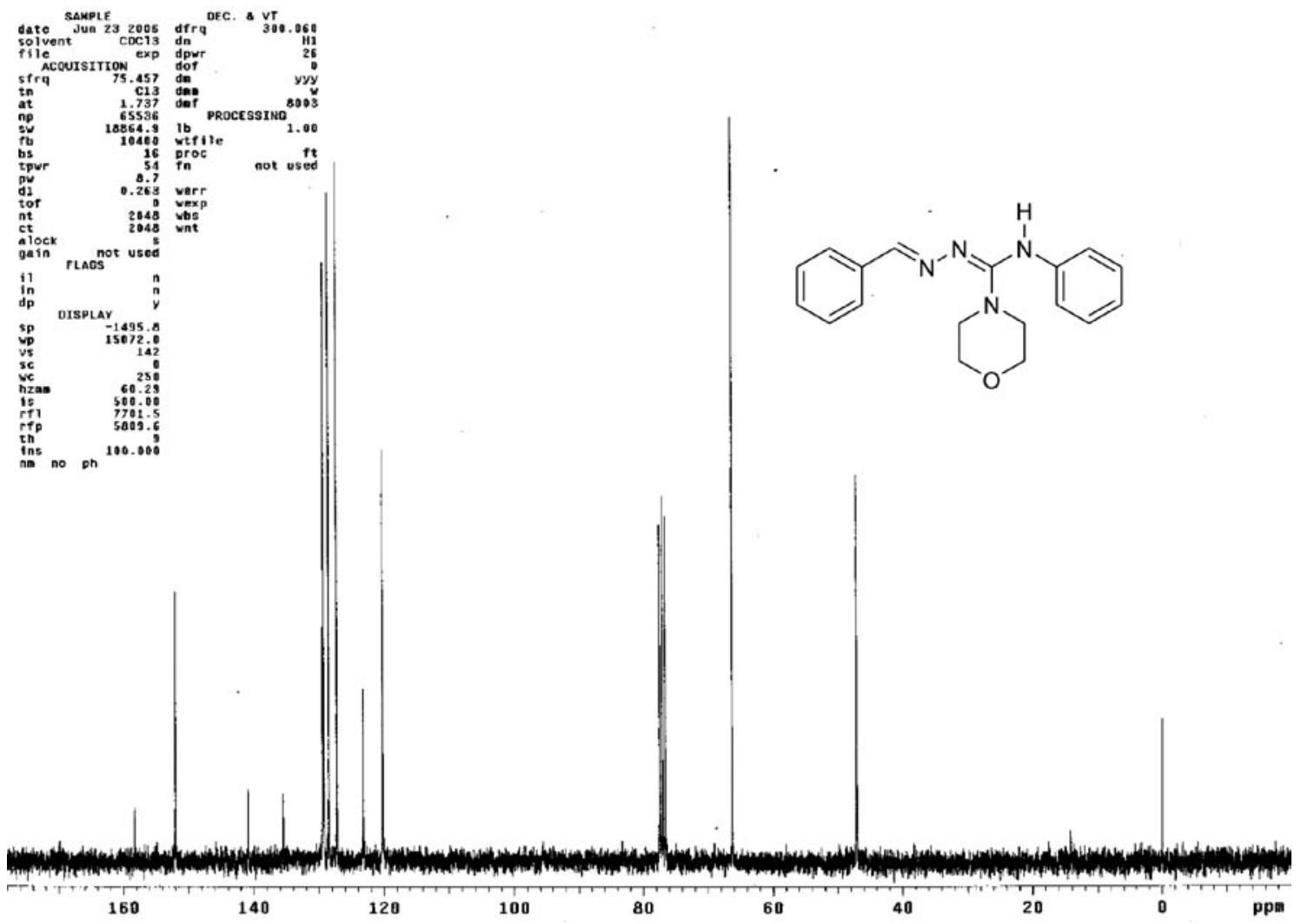

Figure S22. Full ${ }^{13} \mathrm{C}$ NMR spectrum of compound $\mathbf{2 k}\left(\mathrm{CDCl}_{3}\right)$. 